\title{
The ecomorphology of the shell of extant turtles and its applications for fossil turtles
}

\author{
Laura Dziomber ${ }^{\text {Corresp., } 1,2}$, Walter G Joyce ${ }^{1}$, Christian Foth ${ }^{1}$ \\ 1 Department of Geosciences, University of Fribourg, Fribourg, Switzerland \\ 2 Institute of Plant Sciences \& Oeschger Centre for Climate Change Research, University of Bern, Bern, Switzerland \\ Corresponding Author: Laura Dziomber \\ Email address: laura.dziomber@ips.unibe.ch
}

Turtles are a successful clade of reptiles that originated in the Late Triassic. The group adapted during its evolution to different types of environments, ranging from dry land to ponds, rivers, and the open ocean, and survived all Mesozoic and Cenozoic extinction events. The body of turtles is characterized by a shell, which has been hypothesized to have several biological roles, like protection, thermal and $\mathrm{pH}$ regulation, but also to be adapted in its shape to the ecology of the animal. However, only few studies have investigated the relationships between shell shape and ecology in a global context or clarified if shape can be used to diagnose habitat preferences in fossil representatives. Here, we assembled a three-dimensional dataset of 69 extant turtles and 3 fossils, in particular, the Late Triassic Proganochelys quenstedtii and Proterochersis robusta and the Late Jurassic Plesiochelys bigleri to test explicitly for a relationship between shell shape and ecology. 3D models were obtained using surface scanning and photogrammetry. The general shape of the shells was captured using geometric morphometrics. The habitat ecology of extant turtles was classified using the webbing of their forelimbs as a proxy. Principal component analysis (PCA) highlights much overlap between habitat groups. Discriminant analyses suggests significant differences between extant terrestrial turtles, extant fully aquatic (i.e., marine and riverine) turtles, and an unspecialized assemblage that includes extant turtles from all habitats, mostly freshwater aquatic forms. The paleoecology of the three fossil species cannot be determined with confidence, as all three fall within the unspecialized category, although Plesiochelys bigleri plots closer to fully aquatic turtles, while the two Triassic species group closer to extant terrestrial forms. Although the shape of the shell of turtles indeed contains an ecological signal, it is overall too weak to uncover using shell shape in paleoecological studies, at least with the methods we selected. 


\section{The ecomorphology of the shell of extant turtles and}

\section{2 its applications for fossil turtles}

4 Laura Dziomber ${ }^{1,2}$, Walter G. Joyce ${ }^{1}$, Christian Foth ${ }^{1}$

$6 \quad{ }^{1}$ Department of Geosciences, University of Fribourg, Fribourg, Switzerland

$7 \quad{ }^{2}$ Institute of Plant Sciences \& Oeschger Centre for Climate Change Research, University of

8 Bern, Bern, Switzerland

9

10 Corresponding Author:

11 Laura Dziomber,

12 Institute of Plant Sciences \& Oeschger Centre for Climate Change Research, University of Bern,

13 Bern, Switzerland

14 Altenbergrain 21, 3031 Bern, Switzerland

15 Email address: laura.dziomber@gmail.com

17 Abstract

18 Turtles are a successful clade of reptiles that originated in the Late Triassic. The group adapted

19 during its evolution to different types of environments, ranging from dry land to ponds, rivers,

20 and the open ocean, and survived all Mesozoic and Cenozoic extinction events. The body of

21 turtles is characterized by a shell, which has been hypothesized to have several biological roles,

22 like protection, thermal and $\mathrm{pH}$ regulation, but also to be adapted in its shape to the ecology of 
23 the animal. However, only few studies have investigated the relationships between shell shape

24 and ecology in a global context or clarified if shape can be used to diagnose habitat preferences

25 in fossil representatives. Here, we assembled a three-dimensional dataset of 69 extant turtles and

263 fossils, in particular, the Late Triassic Proganochelys quenstedtii and Proterochersis robusta

27 and the Late Jurassic Plesiochelys bigleri to test explicitly for a relationship between shell shape

28 and ecology. 3D models were obtained using surface scanning and photogrammetry. The general

29 shape of the shells was captured using geometric morphometrics. The habitat ecology of extant

30 turtles was classified using the webbing of their forelimbs as a proxy. Principal component

31 analysis (PCA) highlights much overlap between habitat groups. Discriminant analyses suggests

32 significant differences between extant terrestrial turtles, extant fully aquatic (i.e., marine and

33 riverine) turtles, and an unspecialized assemblage that includes extant turtles from all habitats,

34 mostly freshwater aquatic forms. The paleoecology of the three fossil species cannot be

35 determined with confidence, as all three fall within the unspecialized category, although

36 Plesiochelys bigleri plots closer to fully aquatic turtles, while the two Triassic species group

37 closer to extant terrestrial forms. Although the shape of the shell of turtles indeed contains an

38 ecological signal, it is overall too weak to uncover using shell shape in paleoecological studies,

39 at least with the methods we selected.

\section{Introduction}

42 Turtles represent a remarkable group of tetrapods due to the presence of an ossified shell. The

43 clade Testudinata (sensu Joyce, Parham \& Gauthier, 2004) is defined by the presence of this trait

44 and is represented by more than 350 extant species (Turtle Taxonomy Working Group, 2017)

45 and a rich fossil record that reaches back to the Late Triassic (Młynarski, 1976). A number of 
46 other groups of tetrapods convergently acquired an armored body plan as well, in particular

47 armadillos (Chen et al., 2011), ankylosaurs (Hayashi et al., 2010), aetosaurs (Desojo et al.,

48 2013), and placodonts (Westphal, 1976), but none have proven to be particularly successful, at

49 least in regard to phylogenetic longevity, biogeographic distribution, diversity, or disparity.

\section{The turtle shell}

52 The shell is a common characteristic of all turtles but subject to substantial morphological

53 variation from one species to the other (Pritchard, 2008). It is universally composed of the dorsal

54 carapace and the ventral plastron. From an anatomical perspective, the shell is a composite of the

55 dermis with underlying, preexisting structures, in particular the dorsal ribs, dorsal vertebrae,

56 gastralia, the clavicle, interclavicle, and cleithra (Lyson et al., 2013a, b). The resulting bones of

57 the carapace of a typical turtle are called the neurals, costals, nuchal, peripherals, and pygals

58 (Fig. 1D), those of the plastron the entoplastron and the epi-, hyo-, meso-, hypo-, and

59 xiphiplastra (Zangerl, 1969, Fig. 1E). The bony shell is protected towards the outside by a layer

60 of keratinous, epidermal scutes, but these are secondarily reduced in trionychids (softshell

61 turtles), carettochelyids (pig-nosed turtles), and dermochelyids (leatherback turtles). The scutes

62 of the carapace of a typical turtle are termed cervicals, vertebrals, pleurals, and marginals (Fig.

63 1D), and those of the plastron gulars, extragulars, humerals, pectorals, abdominals, femorals, and

64 anals (Zangerl, 1969; Hutchison and Bramble, 1981, Fig. 1E). The number and the contacts of

65 the bony and epidermal elements vary immensely across turtles and can both be used to diagnose

66 species and to reconstruct phylogenetic relationships. It is therefore not surprising that a large

67 body of literature is dedicated to documenting this type of variation to the turtle shell. 
68

The turtle shell is thought to provide several evolutionary advantages, including protection, pH control, or thermal regulation (Jackson, 2000; Pritchard, 2008; Magwene and Socha, 2012). The presence of this full body armor, however, is thought to constrain other bodily functions, in particular feeding, locomotion, reproduction, and respiration. A number of shell shapes have developed as a compromise. For instance, teardrop-shaped shells (e.g., the chelonioid Chelonia mydas) are more typical for turtles with aquatic habits, especially those that live in open marine environments (Wyneken, 1996), while highly domed shells (e.g., the testudinid Stigmochelys pardalis) are prevalent among turtles with terrestrial habitats (Domokos and Varkoni, 2008). A large diversity of additional morphologies can be observed, including the oval and tectiform shells of many riverine turtles (e.g., emydid Graptemys geographica) or the rounded and greatly flattened shells of many trionychids (e.g., Apalone spinifera). Given that correlations appear to exist between shell shape and ecology, paleontologists have historically been tempted to reconstruct the paleoecology of fossil turtles by reference to their shell shape, but studies have been lacking that explicitly tested this relationship.

\section{Morphometrics in turtles}

A broad selection of studies have recently focused on finding correlations between the ecology of extant turtles and their cranial or post-cranial morphology, including morphometrics (e.g., Joyce \& Gauthier, 2004; Domokos \& Vàrkonyi, 2008; Benson et al., 2011; Lichtig \& Lucas, 2017), histology (e.g., Scheyer \& Sander, 2007), geometric morphometrics (e.g., Claude et al., 2003, 2004; Depecker et al., 2006; Rivera, 2008; Rivera \& Claude, 2008; Stayton, 2011; Foth, Rabi \& Joyce, 2017; Foth et al., 2019), and Finite Element Analysis (e.g., Stayton, 2009; Polly et al., 2016). A number of these studies were performed with the explicit goal of finding 
91 correlations among extant turtles to reconstruct the paleoecology of the oldest known fossil

92 turtles, a topic with considerable interest regarding the origin and early evolution of the group.

93 Two taxa have been at the center of these studies: Proganochelys quenstedtii Baur, 1887 and

94 Proterochersis robusta Fraas, 1913 from the Late Triassic of Germany. Proganochelys

95 quenstedtii was originally argued to have had been a fresh-water aquatic bottom walker based on

96 its low shell and details in femoral anatomy (Gaffney, 1990), while Proterochersis robusta was

97 tacitly assumed to be terrestrial based on its highly domed shell (e.g., Fraas, 1913; Lapparent de

98 Broin, 2001). Joyce \& Gauthier (2004) used morphometric measurements from forelimb bones,

99 in particular the relative length of the humerus, ulna, and hand, as a proxy for the habitat

100 preferences of extant and fossil turtles. For this study, extant turtles were classified into six

101 different ecological categories ranging from completely terrestrial to completely aquatic. The

102 data shows a strong correlation between the relative length of the hand and the ecology of extant

103 turtles, with terrestrial turtles having shorter hands than aquatic ones, and predicts Proganochelys

104 quenstedtii to have been terrestrial. Proterochersis robusta was not included in this study, as its

105 forelimbs are not preserved. This conclusion was broadly corroborated by Scheyer \& Sander

106 (2007), who noted through a study of bone histology that the bone microstructure of

107 Proganochelys quenstedtii and Proterochersis robusta more closely resembles that of extant

108 terrestrial turtles than that of extant aquatic turtles. Benson et al. (2011) concluded based on shell

109 cross-section morphometrics of the shell of extant turtles, as quantified from photographs, that

110 Proterochersis robusta was likely semi-aquatic, although it is important to note that the habitat

111 categories of Benson et al. (2011) do not overlap with those of Joyce et al. (2004). The recent

112 study of Lichtig \& Lucas (2017), finally, inferred a freshwater aquatic ecology for

113 Proganochelys quenstedtii and a terrestrial ecology for Proterochersis robusta using ratios from 
114 the shell, in particular maximum carapace width to maximum plastron and carapace length to

115 maximum carapace height. It therefore appears that different lines of evidence yield conflicting 116 results.

117

Aims of the study

119 Previous studies that assessed the ecology of fossil turtles using the turtle shell as a source of

120 information only utilized select aspects of the shell. The initial aim of this study is to first test for

121 correlations between ecology and the entire shell shape of extant turtles using three-dimensional

122 geometric morphometrics in combination with multivariate analyses. The correlations observed

123 among extant turtles are then applied to the Late Triassic turtles Proganochelys quenstedtii and

124 Proterochersis robusta and the Late Jurassic turtle Plesiochelys bigleri.

125

\section{Material and Methods}

\section{Institutional abbreviations}

128 FMNH, Field Museum of Natural History Chicago, Illinois, USA; NMB, Naturhistorisches

129 Museum Basel, Switzerland; MHNF, Museum d'Histoire Naturelle de Fribourg, Switzerland;

130 SMNS, Staatliches Museum für Naturkunde Stuttgart, Germany; MJSN, JURASSICA Museum, 131 formerly Musée Jurassien des Sciences Naturelles, Porrentruy, Switzerland.

Taxonomic sampling

134 The sample of extant turtles includes species representing all turtle clades and habitat

135 preferences. Sampling was strictly limited to specimens collected as adults from the wild, as the

136 shell of many turtles grows into an unnatural shape when kept in captivity, such as the pyramidal 
137 scutes seen in captive-raised tortoises (Wiesner \& Iben, 2003; Gerlach, 2004). To avoid biases

138 caused by sampling different ontogenetic stages, sampling was furthermore restricted to

139 skeletally mature individuals. The sole exception to this rule is the giant leatherback turtle

140 Dermochelys coriacea, the only representative of its clade, for which a juvenile specimen was

141 chosen (carapace length ca. $13 \mathrm{~cm}$ ), since no intact adult specimens were available for study.

142 Finally, sampling was limited to specimens with complete shells, including naturally articulated

143 bridges, that lack scute abnormalities, shell deformations (e.g., kyphosis), or pronounced

144 asymmetry. Sex was disregarded as a selection criterion, as most specimens housed in

145 collections, especially skeletal specimens, are not sexed and as the sex of turtles is only known to

146 influence the overall shape of the shell in a subtle manner (Pritchard, 2008). To substantially

147 increase sample size, specimens were included with varying preservation methods, including dry

148 skeletal specimens, mummified specimens, and specimens conserved in ethanol. The inclusion of

149 ethanol preserved individuals particularly allowed sampling trionychids and the leatherback

150 turtle Dermochelys coriacea.

151 To optimize phylogenetic coverage, we attempted to sample at least one species of each

152 currently recognized genus of extant turtle (TTWG, 2017). Several species were sampled,

153 however, for genera that exhibit ecological plasticity, in particular Cuora, Terrapene, and

154 Rhinoclemmys, genera that contain both aquatic and terrestrial species. The final primary dataset

155 consists of 69 species of extant turtles (see Table 1) that represent all major turtle clades. Generic

156 sampling exceeds 50\% for all clades but Podocnemididae (detailed in Supplementary Files,

157 Table S1).

158 In addition to recent turtles, the sample furthermore includes three species of fossil turtles: the

159 thalassochelydian Plesiochelys bigleri Püntener, Anquetin, \& Billon-Bruyat, 2017 from the Late 
160 Jurassic of Switzerland, Proganochelys quenstedtii from the Late Triassic of Germany, and

161 Proterochersis robusta from the Late Triassic of Germany. For the fossil turtles, the best-

162 preserved specimens were chosen to represent each species (see Table 1), except in the case of

163 Proganochelys quenstedtii, for which a cast of SMNS 16980 was scanned (Gaffney, 1990).

164

165 Acquisition of 3D models

166 We generated 3D models of turtle shells using two main techniques. The 3D scanner Artec Space

167 Spider, which produces 3D models utilizing structured light, was used for most specimens with a

168 length smaller than $60 \mathrm{~cm}$. The reconstruction of the models was done using Artec Studio

169 Professional 10. Larger specimens were sampled using close-range photogrammetry. The

170 models obtained were computed using the software Agisoft Photoscan Professional based on

171 photographs taken with an Olympus E-M10 camera. All 3D models were generated by us, expect

172 the one of Plesiochelys bigleri, which was made available by Raselli and Anquetin (2019). All

173 3D models reconstructed by us for this project are available on MorphoSource (Dziomber, Joyce

174 and Foth, 2020; see Supplementary Files, Table S2 for the DOI of these specimens).

175

176

Morphometric measurements

177 Some of the previous geometric morphometric studies of the turtle shell attempted to capture its

178 morphology by utilizing as many type-I landmarks as possible, in particular those created by the

179 contacts of the bones and the overlying epidermal scutes (e.g., Claude et al., 2003; Angielczyk \&

180 Sheets, 2007). As various groups of turtles lack all or some dermal bones or epidermal scutes

181 (e.g., carettochelyid, dermochelyids, trionychids), use of type-I landmarks defined by these

182 structures precludes utilizing the full spectrum of morphotypes developed by turtles over the

183 course of their history. In addition, as the shape and placement of the bones and epidermal scutes 
184 on the shell of a turtle are strongly influenced by phylogenetic history, use of type-I landmarks

185 defined by these structures is optimal for capturing the phylogenetic information held by the

186 subparts of the shell, not the shape of the shell in itself. We therefore here implement an

187 alternative approach that uses a set of ten homologous landmarks and 255 semilandmarks

188 distributed on twelve curves (Fig. 1). The landmarks represent geometric points, in particular the

189 anterior-most and posterior-most points along the midline of the carapace (landmarks 1 and 2)

190 and plastron (landmarks 3 and 4), the anterior and posterior limits of the contact of the axillary

191 (landmarks 5 and 8) and inguinal buttress (landmarks 6 and 7) with the peripheral series, and the

192 median point between the buttresses, typically the hyo/hypoplastral contact with the peripheral

193 series (landmarks 9 and 10). These primary landmarks define the start and end points of the

194 twelve semi-landmark curves (Fig. 1), in particular the outline of the carapace (curves C1 and

$195 \mathrm{C} 2$ ), the doming of the carapace (curves C3 and C12), the midline and cross section of the

196 plastron (curves C4 and C11), the outline of the anterior and posterior plastral lobes (curves C5,

$197 \mathrm{C} 7, \mathrm{C} 8, \mathrm{C} 10$ ), and the bridge (i.e., contact of the plastron with the carapace, curves C6 and C9).

198 Landmarks were set directly onto the 3D models using the software Checkpoint (Stratovan).

199 The curves were captured in a two-step process. For the first step, semilandmarks were manually

200 set along the curves of the specimen using the "curve" function of Checkpoint. The resulting

201 curves are not yet comparable to one another, as they utilize a different number of unevenly set

202 semilandmarks. The primary semilandmarks curves were therefore resampled in $R$ v3.6.3 (R

203 Core Team, 2020) to produce an equidistant repartition of 255 points along the curves (Gunz \&

204 Mitteroeker, 2013) using the digit.curves function of the package geomorph v3.2.1 (Adams \&

205 Otarola-Castillo, 2013; Adams, Collyer \& Kaliontzopoulou, 2020). 
In order to discuss which components provide the most variation and identify which

207 parameters of the shell represent the best proxy to infer the ecology of turtles, we produced four

208 datasets with different landmarks and semilandmarks configurations (Table 2, Fig. 2) capturing

209 several aspects of the shell. SET 1 utilizes all landmarks, SET 2 the perimeter of the carapace,

210 SET 3 the transverse cross-section, a proxy for doming, and SET 4 the cross-section, a proxy for

211 the hydrodynamics of the shell.

212

213 Classification of habitat preferences

214 In order to investigate the relationships between habitat preferences and shell shape among the

215 extant turtles in the sample, it is necessary to classify them by their ecology (Table 1). As

216 gradual variation is apparent between habitat categories that makes it difficult to implement this

217 step, we used the method of Foth et al. (2019), which categorizes turtles by the development of

218 the webbing of their forelimbs as an ecological proxy (Table 3, Fig. 3). This is based on the

219 justifiable assumption that the degree of webbing correlates with the amount of time the turtle

220 spends in water. In contrast to defining ecological categories based on imprecise descriptions

221 from the literature (e.g., "terrestrial," "poorly aquatic", "semi aquatic" or "fully aquatic"), this

222 approach is more objective, as webbing can be easily observed in museum specimens or the

223 scientific literature (e.g., Ernst \& Barbour, 1989; Bonin, Devaux \& Dupré, 1998). Our five

224 primary categories include "no webbing" (0), "poorly webbed" (1), "fully webbed," with

225 webbing reaching the base of the claws (2), "extensive webbing," with at least one claw being

226 enveloped (3), and "flippers" (4). The scoring for each species is provided in Table 1. We also

227 tested an alternative classification, which is a combination of the previously described categories,

228 defined as "terrestrial" (including category 0, "not webbed"), "semi-aquatic" (including category 
2291 and category 2 , "poorly webbed" and "fully webbed") and "aquatic" (including category 3 and

230 category 4, "extensive webbing" and "flippers").

231

232 Analyses of morphometric data

233 In order to compare the shapes of the turtle shells we obtained, all sets of landmarks were scaled,

234 translated, and rotated using Generalized Procrustes superimposition (GPA: Rohlf \& Slice,

235 1990). This procedure was undertaken in $R$ using the function gpagen in geomorph. The

236 semilandmarks were slid using bending energy (Gunz, Mitteroecker \& Bookstein, 2005).

237 To test for the impact of allometric shape variation we used the log-transformed centroid size

238 of the specimens of each dataset and produced a linear regression against Procrustes shape (see

239 Drake \& Klingenberg, 2008). The regression was computed using the function procD.lm in the $R$

240 package geomorph. The ANOVA (analysis of variance) was performed with 1,000 permutations.

241 Then, we performed a Principal Component Analysis (PCA), which is a commonly used

242 method to convert a set of data into a set of independent variables. The PCA was computed using

243 the function gm.prcomp in the $R$ package geomorph.

244 We first tested for a correlation between ecology and shell shape using a linear discriminant

245 analysis (LDA), which distinguishes morphological differences between groups (Fisher, 1936;

246 McLachlan, 2004). LDA identifies the axes that maximize the separation between multiple

247 classes, in our case the ecological categories we select. LDA is based on those principal

248 components (PC) that contain significant shape information. The number of significant PC

249 scores kept was estimated using the broken-stick method (Frontier, 1976; de Vita 1979; Jackson,

250 1993, see Supplementary files, Fig. S1). The LDA tested the performance of an a priori

251 classification model and assigned specimens of unknown ecology to a specific category. The 
252 LDA was performed using the function $l d a$ from the package MASS (Ripley et al., 2013) and was

253 used for the calculations. To test the accuracy of the predictions and prevent overfitting, we

254 performed the analysis with and without leave-one-out cross-validation.

255 Furthermore, we also performed a phylogenetic flexible discriminant analysis (pFDA). In

256 contrast to LDA, pFDA addresses the impact of phylogeny on the data to provide predictions

257 (Motani \& Schmitz, 2011). The phylogenetic tree used for the pFDA is based on Pereira et al.

258 (2017), which is the best sampled molecular tree available for extant turtles. The original tree,

259 which consists of 294 extant turtles, was pruned to only include the taxa present in the sample

260 and then time-calibrated based on Joyce et al. (2013). The extinct turtles Proganochelys

261 quenstedtii and Proterochersis robusta were then added as stem-turtles following Joyce (2007),

262 with Proganochelys quenstedtii as the most basal turtle in the tree. Plesiochelys bigleri was

263 placed as sister group to Cryptodira following Anquetin, Püntener \& Joyce (2017; Fig. 4). The

264 ages for the time calibration of the fossil taxa was taken from Joyce (2017) and Anquetin,

265 Püntener \& Joyce, 2017). Alternative positions for these taxa can be found, among others, in

266 Szczygielsky and Sulej (2016) or Evers and Benson (2019). The strength of the phylogenetic

267 signal is estimated by the Pagel's lambda-value $(\lambda)$, which varies from 0 to 1 , with 0 denoting

268 the lack of a phylogenetic signal and 1 denoting a strong phylogenetic signal under Brownian

269 motion (Pagel, 1999). This corrects for the phylogenetic bias that can occur in the dataset. The

270 discriminant analysis hereby attempts to predict the ecology of each data point based on the input

271 data. This step produces the confusion matrix that summarize the results. The R code used for the

272 pFDA was originally published by Motani \& Schmitz (2011), which in return was adapted from

273 Hastie et al. (1994). The code was adapted for the purpose of this study. 


\section{Results}

276

277

278

279

280

281

282

283

284

285

286

287

288

289

290

291

292

293

294

295

296

297

\section{Allometry}

The results of the linear regression and the ANOVA indicate no correlation between shape and $\log$-transformed centroid size $\left(\mathrm{R}^{2}=0.0235, \mathrm{P}\right.$-value $=0.134$; Fig. 5), indicating the absence of an interspecific allometric signal. We, therefore, did not calculate the non-allometric residuals of the Procrustes coordinates.

\section{Principal Component Analysis (PCA)}

For SET1 (Fig. 6A), PC1 explains $28.81 \%$ of the total shape variation. Most of the variation pertains to the height of the dome of the shell and the relative size of the plastron, in that highly domed shells have enlarged plastra (negative PC scores) and flattened shells have small plastra (positive PC scores). Surprisingly, turtles categorized by the presence of flippers (category 4) are scattered across the plot. PC2 explains $14.5 \%$ of the variation. Like PC1, it pertains to the height of the dome and the relative size of the plastron, in that highly domed shells have a small plastron (negative PC scores) and flattened shells possess an enlarged plastron (positive PC scores). The PCA plot for SET1 shows an overlap of most ecological categories. Proterochersis robusta groups with non-webbed (category 0 ) and poorly-webbed (category 1) turtles with domed-shells, while Proganochelys quenstedtii and Plesiochelys bigleri are closer to turtles with flattened shells.

SET2, which describes the outline of the carapace (Fig. 6B), PC1 explains $37.41 \%$ of the total variation. The shape of the outline of the shell varies from elongate (negative scores) to rounded, being almost as wide as long (positive scores). PC2 explains $19.25 \%$ of the total variation and captures shell width from broad (negative PC scores) to narrow (positive scores). Turtles with 
298 flippers (category 4) plot closely together but are still nested with the group of fully webbed

299 turtles (category 2). The included fossils do not group with any particular category. In addition,

300 the fossils tend towards positive PC1 scores, in the left part of the graph, which corresponds to a

301 more rounded morphology.

302 PC1 of SET 3, which captures the transverse cross-sectional shape of the shell, explains

$30368.44 \%$ of the total variance, most of which pertains to the height of the dome, from flat

304 (negative scores) to highly domed (positive scores) (Fig. 6C). PC2 carries $16.71 \%$ of the total

305 variance and mostly explains the cross-section of the shell from domed carapaces with a flat

306 plastron (negative scores) to flattened carapaces with a convex plastron (positive scores). As with

307 the previous SETs, the ecological categories strongly overlap each other. Proganochelys

308 quenstedtii and Plesiochelys bigleri plot on the negative site of PC1, while Proterochersis

309 robusta is found on the opposite of PC1. Part of the overlap is explained by the presence of the

310 outliers for various categories, in particular the pancake tortoise (Malacochersus tornieri), which

311 is a greatly flattened terrestrial turtle, or the leatherback turtle (Dermochelys coriacea), which is

312 a marine turtle with a strongly convex plastron.

313 SET4 investigates shape variation to the longitudinal cross-section of the shell (Fig. 6D). PC1

314 explains $44.4 \%$ of the total variance. Turtles represented by negative scores have a domed

315 morphology and a long plastron, in which the dome is accentuated in the anterior part of the

316 shell. Turtles represented by positive scores capture flattened carapaces with short plastra. Here,

317 the carapace overhangs the posterior end of the plastron. PC2 represents $27.1 \%$ of the total

318 variance. Negative scores correspond to a flat-shaped carapace and elongated plastron. Positive

319 scores describe a domed carapace, with the maximum curvature in the posterior section of the

320 shell that overhangs the plastron. As with the other SETs, the PCA shows a big overlap in the 
321 distribution of various ecological categories. Trionychids nevertheless plot closely together in the

322 positive part of PC1 scores. Proterochersis robusta plots close to the terrestrial turtles (category

323 0), while Proganochelys quenstedtii plots in the "fully webbed" range (category 2). Plesiochelys

324 bigleri plots towards the left of the graph (see Supplementary Files, Supplementary Table S3).

325

326 Linear discriminant analysis results

327 The recognition of the ecological categories by the confusion algorithm for the linear

328 discriminant analysis (LDA) is variable depending on the subset (SET) used (Table 4, detailed

329 tables are provided in the Supplementary Files, Table S4). The main error is in a range between

$33025 \%$ and $40 \%$ of misclassification for each SET. However, SET1 (25.3\% of misclassification)

331 gives the best results as compared to the other SETs. In fact, in SET1, all categories are

332 recognized at least at a rate of 50\%. In SET2 and SET4, species defined as "poorly webbed"

333 (category 1) are not well identified (38\%). For the SET3, which represents the transverse cross-

334 section, the categories flippers (category 4, 60\%, while 100\% recognized for all the other SETs)

335 and poorly webbed (category 1, 13\%) are poorly distinguished. The outcome of the confusion

336 matrix gives the most robust results for SET1, among all the arrangements. The use of all data is

337 therefore better than the use of just one component. After cross-validation, the total error of

338 correct identification increased moderately for SET1 (32\%), SET2 (36\%) and SET4 (37\%, see

339 Supplementary material, Table S4 for all confusion matrices). While all categories are still

340 recognized at a rate of minimum 50\% for SET1, recognition of "poorly webbed" turtles (category

341 1) and "extensive webbing" (category 3) drop significantly for SET2 (38\% and 25\%) and SET3

342 (38\% and 0\%). There is also a drop in the recognition for turtles having flippers for SET3 (40\%).

343 On the other hand, "not webbed" turtles (category 0) and "fully webbed" turtles (category 2) 
344 stayed highly stable. These results indicate overfitting of the training data, indicating that the

345 predictions are partially dependent on sample-size. However, the outcome of the confusion

346 matrix using cross-validation still reveals that SET1 performs better than other configurations.

347 For SET1 (Fig. 7A), three groups of extant turtles are discriminated: (1) turtles lacking

348 webbing (category 0); (2) turtles ranging from non-webbed to fully webbed turtles (category 0-

349 2); (3) and turtles with extensive webbing (category 3) and flippers (category 4). For SET2 (Fig.

350 7B), which corresponds to the outline of the carapace, only turtles with flippers (category 4) are

351 well-discriminated, as these taxa all possess a distinctive tear-drop-shaped shell (see mean

352 shapes per category in Supplementary Files, Fig. S2). For SET3 and SET4 (Fig. 7C, D), the

353 webbing categories greatly overlap each other. There is a gap between the two extreme

354 categories (not webbed and flippers) but no category is discriminated. There is a trend along the

355 LD1, with terrestrial adaptations (i.e., no or minor webbing) on the negative side, and aquatic

356 adaptations (i.e., extensive webbing or flippers) on the positive side.

357 The predictions of the webbing (and thus ecology) of the fossil turtles are variable between

358 the SETs (see Fig. 7; Table 5). For SET1, all fossil turtles are identified as having "fully

359 webbed" forelimbs (category 2). However, Plesiochelys bigleri plots just at the limits between

360 "fully webbed" (category 2) and "extensively webbed" and "flipper-shaped" forehand (category 3

361 and 4) and Proterochersis robusta at the limit between "poorly webbed" (category 1) and "fully

362 webbed" (category 2) turtles (Fig. 7A). Proganochelys quenstedtii plots within the "fully

363 webbed" (category 2) turtles. For SET2, the fossil turtles are identified as either fully webbed

364 (category 2) or poorly webbed (category 1), but plot further away from the extant groups, except

365 for Plesiochelys bigleri, which groups with fully webbed (category 2) turtles but was determined

366 to be "poorly webbed" with a probability of 49\% (see Table 5). For SET3, Proterochersis 
367 robusta is predicted to be "fully webbed" (category 2), but only with a probability of $38 \%$. On

368 the other hand, Plesiochelys bigleri is predicted to have been "extensively webbed" (category 3 )

369 with a low probability of $49 \%$ while Proganochelys quenstedtii groups with turtles that are

370 "poorly webbed" (category 1), also with a low probability (47\%). Finally, for SET4,

371 Proganochelys quenstedtii is predicted to have been "poorly webbed" (category 1), while

372 Proterochersis robusta and Plesiochelys bigleri are reconstructed as "fully webbed" (category 2),

373 which is consistent with what can be observed on the graph.

375 Phylogenetic flexible discriminant analysis results

376 The confusion matrix based on the phylogenetic flexible discriminant analysis (pFDA) shows

377 good recognition of ecological variables (expressed by the degree of webbing in the forelimbs)

378 for extant species (Table 6, detailed tables are provided in the Supplementary Files, Table S4).

379 The analysis including all landmarks and curves (SET1) shows consistent results between 50 to

$380100 \%$ accuracy for the different webbing categories. SET2, which describes the outline of the

381 carapace is slightly better regarding the correct identification of most webbing categories, except

382 for minor webbing (category 1). SET3 and SET4, however, fail to identify turtles with minor

383 webbing (category 1 ) and extensive webbing (category 3 ). The outcome in the confusion matrix

384 gives the most solid results for SET1 among all arrangements. Therefore, higher accuracy is

385 gained when using all landmarks and semilandmarks in combination with phylogeny (Table 6).

386 The pFDA results for extant turtles are similar to the LDA results for SET1 and SET2. The

387 distribution, however, is variable for SET3 and SET4. In SET1, the graph is divided into three

388 major groups. One is composed of turtles with not-webbed morphologies, one includes turtles

389 with poorly webbed and fully webbed forelimbs, and a last one with turtles having extensive 
390 webbing and flipper-shaped forelimbs (Fig. 8A). In SET2 only turtles with flippers are well

391 discriminated. The results for SET3 and SET4, show much overlap between all categories. The

392 predictions for fossils are not congruent depending on the arrangement being used. All fossil

393 turtles are predicted to be "minor-webbed" (category 1) to "flipper-shaped" (category 4), which

394 suggests aquatic habitat preferences. However, there is great variability in the predictions

395 depending on the configuration of the dataset (SET1 to SET4). Although Plesiochelys bigleri is

396 resolved as having flippers (category 4) and plots with extant turtles for SET1, the Triassic fossil

397 turtles are resolved as "fully webbed" (2) but plot further away from the extant group.

398 Proganochelys quenstedtii and Proterochersis robusta do not group close together with any

399 other turtle. For SET2, Plesiochelys bigleri is grouped again within the extant group, contrary to

400 Proganochelys quenstedtii and Proterochersis robusta, which are found to be outliers.

401 Plesiochelys bigleri is predicted as poorly webbed" (category 1), while Proterochersis robusta

402 and Proganochelys quenstedtii are predicted to have "flippers" (category 4) and "poorly webbed"

403 (category 1). In SET3, all fossils plot outside of the extant groups, even if the algorithm gives

404 predictions such as extensive webbing (category 3) for Proganochelys quenstedtii, "fully

405 webbed" (category 2) for Plesiochelys bigleri, and "flippers" (4) for Proterochersis robusta

406 (Table 7). For the SET4, the fossils plot again outside of the extant categories and are predicted

407 to be "fully webbed" (category 2) for Proterochersis robusta and Plesiochelys bigleri and as

408 "poorly webbed" (category 1) for Proganochelys quenstedtii.

409

\section{Ecological categories}

411 It is notable that the categories poorly webbed (category 1) and fully webbed (category 2)

412 overlap each other in both LDA and pFDA, just as the categories extensive webbing (category 3 ) 
413 and flippered (category 4). However, the pFDA is not very insightful concerning the

414 webbing/ecology of fossil turtles. To investigate the impact of the categorization done herein, the

415 LDA analysis was performed on the SET1 again using a different combination of categories. In

416 particular, the five previously used categories were reclassified for this purpose into three novel

417 categories, herein defined as "terrestrial" (including category 0 , not webbed), "semi-aquatic"

418 (including category 1 and category 2, poorly webbed and fully webbed) and "aquatic" (including

419 category 3 and category 4 , extensive webbing and flippers). The results of this secondary

420 analysis are provided in the update confusion table (Table 8) and graphs (Fig. 9B).

421 The misclassification rate for the confusion matrix associated with the three new categories

$422(18.4 \%)$ is lower than what is observed in the one with five categories (25.3\%). For instance,

423 semi-aquatic turtles are well recognized (38 of 39), but some aquatic ( 3 over 13) and terrestrial

424 turtles (5 over 17) are still misclassified. However, in general, the dataset containing three

425 categories (Fig. 9B) gives similar results when compared with the original dataset defined by

426 five categories (Fig. 9A). Both groupings show no overlap between the terrestrial and the aquatic

427 categories (see Supplementary Files, Fig. S3). However, the third category of semi-aquatic

428 turtles remains poorly discriminated. When it comes to fossils specimens, the results are similar

429 between the two grouping classifications (Table 9). Plesiochelys bigleri falls between fully

430 webbed (2) and extensive webbing (3) in the first classification model (Fig. 9A) and remains at

431 this position in the second plot (Fig. 9B), between the semi-aquatic and the aquatic category.

432 Moreover, in the model with three categories, Proganochelys quenstedtii and Proterochersis

433 robusta plot further away from the extant groups. It appears that splitting the semi-aquatic

434 category into two (poorly-webbed and fully-webbed) gives a more precise placement for the 
435 Triassic turtles such as they plot closer to the extant groups, even if there is poor discrimination

436 between these two categories.

437

438 Discussion

439

440

441

442

443

444

445

446

448

449

450

451

452

453

454

455 456

457

\section{Results for extant turtles}

In order to determine the paleoecology of extinct species, paleontologists often draw from correlations found among the shape and ecology of extant organisms (e.g., Cassini, 2013 for ungulates; Cooke, 2011 for platyrrhine primates; Forrest, Plummer \& Raaum, 2018 for bovids; Figueirido, Palmqvist \& Pérez-Claros, 2009 for bears; Gomez Cano, Hernandez-Fernandez \& Alvarez-Sierra, 2013 for rodents, Claude et al., 2004 for testudinoids, or Foth, Rabi \& Joyce,

2017 for turtles). This study shows that the three-dimensional shape of the shell of extant turtles, as herein captured using landmarks and semilandmarks curves, allows discriminating with high confidence two primary ecological categories, in particular a terrestrial category, a polyphyletic assemblage that consists of most testudinids and some of the emydids and geoemydids included in our sample, and a highly aquatic category, another polyphyletic assemblage that includes all chelonioids, most trionychids, and some chelydroids included in our sample. All remaining turtles are left behind in a poorly diagnosed, intermediate category which unites an eclectic group of fully terrestrial to highly aquatic turtles with what amounts to a non-specialized continental shell shape. We, therefore, have confidence in using this method to assess the ecology of fossil turtles, with the caveat, however, that it is only possible to recognize two specialized morphotypes.

\section{Results for fossil turtles}


458 We find the results of our pFDA analyses to be dubious, as the Triassic fossil turtles are not

459 grouping anywhere close to any extant turtle, in contrast to the PCA and LDA, where these

460 turtles plot within the morphospace defined by extant members of the group. This placement of

461 the Triassic turtles as outliers in the pFDA graph could be a direct result of time calibration

462 combined with the phylogenetic placement of these turtles at the base of the turtle tree. This

463 hypothesis was explored with a series of tests, including, among others, use of an ultrametric tree

464 (i.e., all fossils were coded as living in the Present) and use of an artificial outgroup (i.e., an all 0

465 outgroup, an all 1 outgroup, and an outgroup with random values) with changing ecology (i.e.,

466 terrestrial versus unknown). In the plots resulting from the use of an ultrametric tree, the Triassic

467 fossils pool with extant turtles, even though their phylogenetic distance has actually increased

468 (see Supplementary file, Fig. S4 and Fig. S5). This makes us question the application of this

469 method on this dataset. The problematic placement of the Triassic fossils as outliers is not solved

470 in any of the six variant analyses using an artificial outgroup, as their position remains mostly

471 unchanged (see Supplementary files, Fig. S6 and Fig. S7). As all pFDA performed resulted in an

472 optimal $\lambda=0$, none of the subsets of the data contain a phylogenetic signal under Brownian

473 motion (Pagel, 1999; Motani \& Schmitz 2011). This may have led to the curious placements of

474 Proterochersis robusta and Proganochelys quenstedtii. As shell shape seems to be independent

475 from turtle phylogeny, a phylogenetic correction of the data is unjustified. Consequently, we 476 restrict ourselves to discussing the LDA results only.

477

478 Paleoecology of Plesiochelys bigleri

479 Plesiochelys bigleri was included in the study to test the impact of fossils on the study, but also

480 because the paleoecology of plesiochelyids remains poorly resolved as either riverine 
481 (Rütimeyer, 1873), near-shore marine (Billon-Bruyat et al., 2005), or marine (Bräm, 1965). This

482 uncertainty is based, in part, on the realization that the sediments that preserve plesiochelyids 483 contain a mixture of continental to marine faunas (Comment, 2015), the fact that no complete 484 limbs are yet preserved (Anquetin, Püntener \& Joyce, 2017), and that the geochemical study of 485 Billon-Bruyat et al. (2005) lacks catalog numbers for the specimens included in the study that 486 would allow a verification of their results (Anquetin, Püntener \& Joyce, 2017).

487 In the LDA using five categories, Plesiochelys bigleri is predicted to be "fully webbed" and 488 plots at the margin of "fully webbed" turtles close to turtles with "extensive webbing". The 489 equivalent analysis using three categories predicts this fossil to be "intermediate," but it plots 490 again within this group towards the margin with "specialized aquatic turtles." These predictions

491 translate into a non-specialized aquatic morphology that is broadly consistent with riverine to 492 costal habitats. Although this does not clarify the ecology of this turtle beyond the debate 493 outlined above, it at least provides independent support for a highly aquatic lifestyle and make 494 the prediction that this animal will reveal to have relatively elongate limbs, but not fully formed 495 flippers.

496

Paleoecology of Proterochersis robusta

Proterochersis robusta has traditionally been thought to have had been a terrestrial turtle (Fraas, 1913; Mlynarski, 1976; Lapparent de Broin, 2001), but this was likely based on the highly

500 domed habitus of the shell combined with the continental sediments from which it was

501 recovered. The study of Scheyer \& Sander (2007) confirmed this assertion more recently using

502 bone histology, but Benson et al. (2011) soon after concluded upon a semi-aquatic lifestyle based 
503 on the cross-section of this animal. Lichtig \& Lucas (2017) finally concluded upon terrestrial

504 habitat preferences, once again, mostly based on shell ratios that pertain to the doming.

505 The LDA that utilizes five categories predicts that Proterochersis robusta is "fully webbed."

506 It also plots at the margin of "fully webbed," but close to turtles that are "poorly webbed" such as

507 the emydid Emys blandingii and the chelid Platemys platycephala, which are poor swimmers,

508 but also the geoemydids Cuora amboinensis and Melanochelys trijuga, which are described as

509 semi-aquatic turtles (Ernst \& Barbour, 1989). The analysis that utilizes three categories, by

510 contrast, predicts an "intermediate" ecology, which corresponds to a non-specialized shell shape

511 consistent with continental habitat preferences, including fully aquatic, semi-terrestrial, or fully

512 terrestrial. It is interesting to note that this highly domed species does not group with today's

513 highly domed specialized terrestrial tortoises, but rather with the emydid Emys orbicularis, and

514 the geoemydids Mauremys reevesii and Heosemys spinosa, which are also described as semi-

515 aquatic (Ernst \& Barbour, 1989). We therefore interpret these results as deeply ambiguous but

516 note that depositional environments strongly favor a dry continental setting for this turtle, which

517 is consistent with shell histology, and not contradicted by shell shape either.

518

519

Paleoecology of Proganochelys quenstedtii

520 Proganochelys quenstedtii was initially believed to be terrestrial, despite its relatively low

521 domed shell, which was interpreted as being crushed (Fraas, 1899; Jaekel, 1914). Gaffney (1990)

522 noted similarities in the shape of the femur with Macrochelys temminckii and concluded upon a

523 possible bottom walking adaptation by reference to the work of Zug (1971). Joyce \& Gauthier

524 (2004) suggested terrestrial habitat preferences for this taxon based on forelimb proportions,

525 which was soon after confirmed by Scheyer \& Sander (2007) using bone histology. Joyce 
526 (2015), more recently, presented several additional lines of evidence for a terrestrial habitat

527 preference of this taxon, including the presence of osteoderms on the neck and the tail and

528 depositional context, in particular the observation that this turtle is found with continental upland

529 faunas, not intermixed with the rich aquatic low land faunas of the time. Lichtig \& Lucas (2017),

530 by contrast, concluded upon semi-aquatic habitat preferences using shell metrics.

531 The LDA using with five ecological categories predicts for Proganochelys quenstedtii to have

532 been "fully webbed" (category 2). The analysis with three ecological categories on the other hand

533 suggests "intermediate" habitat preference, though the species plots together with Proterochersis

534 robusta towards the edge of the plot, but once again close to semi-aquatic turtles, such as the

535 testudinoids Glyptemys insculpta, Heosemys spinosa, and Emys orbicularis. In our opinion, the

536 analysis suggests that this turtle has a non-specialized shell shape broadly consistent with

537 continental habitat preferences ranging from fully aquatic to fully terrestrial. The majority of

538 independent sources of information nevertheless still point towards a more dry continental

539 signal.

540

541 Do 2D components perform better than 3D data?

542 The relative performance of 2D versus 3D data in geometric morphometrics has recently been

543 discussed (Alvarez \& Perez, 2013; Cardini, 2014; Buser, Sidlauskat \& Summers, 2018;

544 Courtenay et al., 2018; Otárola-Castillo et al., 2018, Hedrick et al., 2019), but the results are

545 divergent depending on the clade and/or the anatomical body region being studied. This analysis

546 utilized several subsets (SET2 to 4) of the same primary dataset of shell morphology (SET1) of

547 extant and fossil turtles. The confusion matrices and the plots confirm higher accuracy in

548 predicting the known ecology of extant turtles for SET1 and SET2. As such, SET2, which uses 
549 the outline of the carapace only, appears to be a better proxy for distinguishing ecological

550 categories in extant turtles than the transverse cross-section (SET3), which were used by

551 Domokos \& Várkonyi (2008) and Benson et al. (2011). Indeed, the latter was found in this study

552 to show the worst correlation with forelimb webbing and the associated habitat preference.

553 Nevertheless, the complete shell shape (SET1) performs slightly better than the outline shape

554 alone (SET2), suggesting that the full shell is needed to characterize the ecology of a turtle.

555

\section{Limits to the study}

557 This study focused on obtaining the 3D shape of a broad set of extant turtles that samples all major clades, but did not consider ontogenetic changes, sexual dimorphism, and variation within genera (see Rivera, 2008, for variation within a species). These concerns may be relevant, considering that some extant turtles display much variation during ontogeny and between the sexes (e.g., Berry \& Shine, 1980; Pritchard, 2008; Vega \& Stayton, 2011). A bigger concern perhaps is that the study only includes few fossil taxa. This was done in part to avoid circularity, but also because intact fossil shells are extremely rare in collections. This has the unfortunate result, however, that shell morphologies not realized by extant turtles for a particular habitat preference or shell morphologies not realized by extant turtles at all are not included in the study, even though they plausibly may have a significant impact. For instance, numerous fossil turtles exist that are believed to have been terrestrial using external data, but that have shell shapes very different from their extant relatives, such as the large, but flat, and often spiked shells of nanhsiungchelyids (e.g., Hirayama, 2001) or the elongate, but flat shells of sichuanchelyids

570 (Joyce et al., 2016). Similarly, numerous taxa thought to be marine, at least by reference to the

571 depositional environment in which they are found, have shells that are similar to freshwater 
572 aquatic turtles, such as Chedighaii barberi or Taphrosphys sulcatus (Gaffney et al., 2006), or

573 display hyperspecialized marine morphologies, such as seen in the thalassochelydians Achelonia

574 formosa and Tropidemys seebachii (Joyce \& Mäuser, 2020) or advanced protostegids such as

575 Archelon ischyros or Calcarichelys gemma (Wieland, 1903; Hooks, 1998). Inclusion of these

576 fossils, if they ever become available in 3D, would likely render the specialized terrestrial versus

577 specialized marine fields categories used in this study even less diagnostic. The impact of fossils

578 was previously illustrated for turtle skulls by Foth, Rabi \& Joyce (2017). Unfortunately, the vast

579 majority of fossils, especially shells, show much taphonomic crushing. In this study, we partially

580 accounted for this by selecting material we felt to be preserved correctly in three dimensions, but

581 we cannot discount subtle plastic deformation. Indeed, a possible additional source of error to

582 our study is usage of a model of Proganochelys quenstedti, which was produced as faithfully as

583 possible by reference to the available, crushed fossil material, but may include subconscious

584 biases of the artist, in addition to taphonomic crushing.

585 As an alternative to the discriminant analysis we used herein, future study may wish to focus

586 on explicitly identifying morphologies associated with particular habitat preferences. For

587 instance, we note informally that the tear-drop shape of extant marine turtles and carettochelyids

588 is uniquely associated with highly aquatic animals, that round, but tectate shells seems to be

589 associated with riverine environments, and self-righting shell shapes, as previously proposed

590 (Domokos \& Varkoni, 2008) with terrestrial habitats, but that generalized shell shapes can occur

591 everywhere. The identification of specialization may therefore provide better results, than the

592 characterization of the morphospace held by all individuals of a certain ecological category. No

593 matter what, as no single source of ecological information appears to be sufficient for the

594 moment to infer the paleoecology of fossil turtles, we recommend a multi-pronged approach, 
595 which includes limb morphology (e.g., Joyce \& Gauthier, 2004), bone histology (e.g., Scheyer \&

596 Sander, 2007), isotopic analysis (e.g., Billon-Bruyat et al., 2005), depositional environments,

597 cranial morphology (e.g., Foth, Rabi \& Joyce, 2017), and, if at all, the full morphology of the

598 shell, not just isolated measurements.

599

\section{Conclusions}

601 This study explicitly sought correlations between turtle shell shape and turtle ecology but ended 602 up questioning the utility of shell shape as a proxy for the paleoecology of fossil turtles. Linear 603 discriminant analysis identified two specialized shell shapes that are associated with extant 604 turtles with highly aquatic versus highly terrestrial habitat preferences. Although these 605 correlations could be applied to the fossil record, they are not particularly useful, as the 606 paleoecology of fossil turtles with these shapes is rarely controversial in the first place. Instead, 607 linear discriminant analysis also highlights that the vast majority of extant turtles exhibit an 608 intermediate morphology, regardless of their habitat preferences. Although we did not include 609 fossil turtles to avoid circularity, we presume that their inclusion would further blur the lines, as 610 numerous fossils we perceive to possess this intermediate shell morphotype are otherwise

611 thought to be highly marine and highly terrestrial. From an evolutionary standpoint, this

612 indicates that the shape of the turtle shell is likely controlled by factors unrelated to ecology. We

613 urge caution for assessing the paleoecology of fossil turtles using shell shape alone. Most

614 importantly, the commonly propagated rule of thumb that a domed shell corresponds to

615 terrestrial ecology, while a flattened one suggests an aquatic lifestyle, should be avoided, as

616 many turtles perceived to be highly domed have an aquatic ecology.

617 


\section{Acknowledgements}

619 We thank numerous people and institutions for providing us with access to specimens in their 620 care, in particular Alan Resetar and Joshua Mata (FMNH), Loic Costeur, Eduard Stöckli, and 621 Ambros Hänggi (NMB), Emanuel Gerber (MHNF), Erin Maxwell and Rainer Schoch (SMNS).

622 We are indebted to Jérémy Anquetin and Irena Raselli (Jurassica Museum) for providing us with 623 a 3D model of Plesiochelys bigleri and to Mónica Angulo-Bedoya (EAFIT) for providing us 624 with the 3D model of Carettochelys insculpta. We thank Olivia Plateau and Bastien Mennecart 625 for useful discussions and comments. We are grateful to Doug Boyer for his help creating the 626 MorphoSource project that holds the 3D models used in this study. We thank Christine Böhmer, 627 Julien Claude, and an anonymous reviewer for comments that greatly improved the manuscript. 628

\section{References}

Adams, D. C., \& Otárola-Castillo, E. (2013). geomorph: an $R$ package for the collection and analysis of geometric morphometric shape data. Methods in Ecology and Evolution, 4, 393-399.

Adams, D. C., Collyer, M. L., \& Kaliontzopoulou, A. (2020). geomorph: software for geometric morphometric analyses. R package version 3.2.1.

Álvarez, A., \& Perez, S. WE. (2013). Two-versus three-dimensional morphometric approaches in macroevolution: insight from the mandible of caviomorph rodents. Evolutionary Biology, 40, 150157.

Angielczyk, K. D. \& Sheets, H. D. (2007). Investigation of simulated tectonic deformation in fossils using geometric morphometrics. Paleobiology, 33, 125-148.

Anquetin, J., Püntener, C., \& Joyce, W. G. (2017). A review of the fossil record of turtles of the clade Thalassochelydia. Bulletin of the Peabody Museum of Natural History, 58, 317-370. 
641 Baur, G. (1887). Ueber den Ursprung der Extremitäten der Ichthyopterygia. Bericht des Oberrheinischen 642 Geologischen Vereins, 20, 17-20.

643 Benson, R. B., Domokos, G., Várkonyi, P. L., \& Reisz, R. R. (2011). Shell geometry and habitat 644 determination in extinct and extant turtles (Reptilia: Testudinata). Paleobiology, 37, 547-562.

645 Berry, J. F., \& Shine, R. (1980). Sexual size dimorphism and sexual selection in turtles (Order 646 Testudines). Oecologia, 44, 185-191.

647 Bonin, F., Devaux, B., \& Dupré, A. (1998). Toutes les tortues du monde. Lausanne: Delachaux et Niestlé. 648 Billon-Bruyat, J. P., Lécuyer, C., Martineau, F., \& Mazin, J. M. (2005). Oxygen isotope compositions of 649 Late Jurassic vertebrate remains from lithographic limestones of western Europe: implications for 650 651 the ecology of fish, turtles, and crocodilians. Palaeogeography, Palaeoclimatology, Palaeoecology,

652 653 $216,359-375$.

Bräm, H. (1965). Die Schildkröten aus dem oberen Jura (Malm) der Gegend von Solothurn. Schweizerische Paläontologische Abhandlungen, 83, 1-190.

Buser, T. J., Sidlauskas, B. L., \& Summers, A. P. (2018). 2D or not, 2D? Testing the utility of, 2D vs. 3D landmark data in geometric morphometrics of the sculpin subfamily Oligocottinae (Pisces; Cottoidea). Anatomical Record, 301, 806-818.

Cardini, A. L. (2014). Missing the third dimension in geometric morphometrics: how to assess if, 2D images really are a good proxy for 3D structures? Hystrix 25, 73-81.

Cassini, G. H. (2013). Skull geometric morphometrics and paleoecology of Santacrucian (late early Miocene; Patagonia) native ungulates (Astrapotheria, Litopterna, and Notoungulata). Ameghiniana, $50,193-217$.

Chen, WE. H., Kiang, J. H., Correa, V., Lopez, M. WE., Chen, P. Y., McKittrick, J., \& Meyers, M. A. (2011). Armadillo armor: mechanical testing and micro-structural evaluation. Journal of the Mechanical Behavior of Biomedical Materials, 4, 713-722. 
665 Claude, J., Paradis, E., Tong, H., \& Auffray, J. C. (2003). A geometric morphometric assessment of the 666 effects of environment and cladogenesis on the evolution of the turtle shell. Biological Journal of 667 the Linnean Society, 79, 485-501.

668 Claude, J., Pritchard, P. C., Tong, H., Paradis, E., \& Auffray, J. C. (2004). Ecological correlates and 669 evolutionary divergence in the skull of turtles: a geometric morphometric assessment. Systematic $670 \quad$ Biology, 53, 933-948.

671 Collyer, M. L., \& Adams, D. C. (2019). RRPP: linear model evaluation with randomized residuals in a 672 permutation procedure. https://CRAN.R-project.org/package=RRPP

673 Comment, G. (2015). Le Kimméridgien d'Ajoie (Jura, Suisse): lithostratigraphie et biostratigraphie de la 674 Formation de Reuchenette. Revue de Paléobiologie, 34, 161-194

675 Cooke, S. B. (2011). Paleodiet of extinct platyrrhines with emphasis on the Caribbean forms:

676 three-dimensional geometric morphometrics of mandibular second molars. Anatomical Record, $677 \quad 294,2073-2091$.

678 Courtenay, L. A., Maté-González, M. Á., Aramendi, J., Yravedra, J., González-Aguilera, D., \&

679 Domínguez-Rodrigo, M. (2018). Testing accuracy in, 2D and 3D geometric morphometric methods 680 for cut mark identification and classification. PeerJ, 6, e5133.

681 Depecker, M., Berge, C., Penin, X., \& Renous, S. (2006). Geometric morphometrics of the shoulder 682 girdle in extant turtles (Chelonii). Journal of Anatomy, 208, 35-45.

683 Desojo, J. B., Heckert, A. B., Martz, J. W., Parker, W. G., Schoch, R. R., Small, B. J., \& Sulej, T. (2013). 684 Aetosauria: a clade of armoured pseudosuchians from the Upper Triassic continental beds.

685 Geological Society, London, Special Publications, 379, 203-239.

686 Domokos, G., \& Várkonyi, P. L. (2008). Geometry and self-righting of turtles. Proceedings of the Royal 687 Society B: Biological Sciences, 275, 11-17.

688 Drake, A. G., \& Klingenberg, C. P. (2008). The pace of morphological change: historical transformation 689 of skull shape in St Bernard dogs. Proceedings of the Royal Society B: Biological Sciences, 275, $690 \quad 71-76$ 
691 Dziomber, L., Joyce, W. G., \& Foth C. (2020). 3D models of: the ecomorphology of the shell of extant 692 turtles and its applications for fossil turtles. Available at:

693 http://www.morphosource.org/Detail/ProjectDetail/Show/project_id/1028.

694 Ernst, C. H. \& Barbour, R. W. (1989). Turtles of the World. Washington D.C.: Smithsonian Institution $695 \quad$ Press.

696 Evers, S. W., \& Benson, R. B. (2019). A new phylogenetic hypothesis of turtles with implications for the 697 timing and number of evolutionary transitions to marine lifestyles in the group. Palaeontology, 62 , $698 \quad 93-134$.

699 Figueirido, B., Palmqvist, P., \& Pérez-Claros, J. A. (2009). Ecomorphological correlates of craniodental 700 variation in bears and paleobiological implications for extinct taxa: an approach based on geometric morphometrics. Journal of Zoology, 277, 70-80.

702

703

704

705

706

707

708

709

710

711

712

713

714

715 716

Fisher, R. A. (1936). The use of multiple measurements in taxonomic problems. Annals of Eugenics, 7 , $179-188$.

Forrest, F. L., Plummer, T. W., \& Raaum, R. L. (2018). Ecomorphological analysis of bovid mandibles from Laetoli Tanzania using 3D geometric morphometrics: Implications for hominin paleoenvironmental reconstruction. Journal of Human Evolution, 114, 20-34.

Foth, C., Rabi, M., \& Joyce, W. G. (2017). Skull shape variation in extant and extinct Testudinata and its relation to habitat and feeding ecology. Acta Zoologica, 98, 310-325.

Foth, C., Evers, S. W., Joyce, W. G., Volpato, V. S., \& Benson, R. B. (2019). Comparative analysis of the shape and size of the middle ear cavity of turtles reveals no correlation with habitat ecology. Journal of Anatomy, 235, 1078-1097

Fraas, E. (1899). Proganochelys quenstedtii Baur (Psammochelys Keuperina Qu.): ein neuer Fund der Keuperschildkröte aus dem Stubensandstein. Jahreshefte des Vereins für Vaterländische Naturkunde in Württemberg, 60, 400-424

Fraas, E. (1913). Proterochersis, eine pleurodire Schildkröte aus dem Keuper. Jahreshefte des Vereins für Vaterländische Naturkunde in Württemberg, 69, 13-30. 
717 Frontier, S. (1976). Étude de la décroissance des valeurs propres dans une analyse en composantes

718 principales: comparaison avec le modd́le du bâton brisé. Journal of Experimental Marine Biology

719 and Ecology, 25, 67-75.

720 Gaffney, E. S. (1990). The comparative osteology of the Triassic turtle Proganochelys. Bulletin of the

$721 \quad$ American Museum of Natural History, 194, 1-263

722 Gaffney, E. S., Tong, H., \& Meylan, P. A. (2006). Evolution of the side-necked turtles: the families

723 Bothremydidae, Euraxemydidae, and Araripemydidae. Bulletin of the American Museum of Natural

$724 \quad$ History, 300, 1-699.

725 Gómez Cano, A. R., Hernández Fernández, M., \& Álvarez-Sierra, M. Á. (2013). Dietary ecology of

726 Murinae (Muridae, Rodentia): a geometric morphometric approach. PLoS ONE, 8, e79080.

727 Hastie, T., Tibshirani, R., \& Buja, A. (1994). Flexible discriminant analysis by optimal scoring. Journal

728 of the American Statistical Association, 89, 1255-1270.

729 Hayashi, S., Carpenter, K., Scheyer, T. M., Watabe, M., \& Suzuki, D. (2010). Function and evolution of

730 ankylosaur dermal armor. Acta Palaeontologica Polonica, 55, 213-229.

731 Hedrick, B. P., Antalek-Schrag, P., Conith, A. J., Natanson, L. J., \& Brennan, P. L. R. (2019). Variability

732 and asymmetry in the shape of the spiny dogfish vagina revealed by, 2D and 3D geometric

733 morphometrics. Journal of Zoology, 308, 16-27.

734 Hirayama, R., Sakurai, K., Chitoku, T., Kawakami, G., \& Kito, N. (2001). Anomalochelys angulata, an

735 unusual land turtle of family Nanhsiungchelyidae (superfamily Trionychoidea; order Testudines)

736 from the Upper Cretaceous of Hokkaido, North Japan. Russian Journal of Herpetology, 8, 127-138.

737 Hooks, G. E. (1998). Systematic revision of the Protostegidae, with a redescription of Calcarichelys

738 gemma Zangerl, 1953. Journal of Vertebrate Paleontology, 18, 85-98.

739 Hutchison, J. H. \& Bramble, D.M. (1981). Homology of the plastral scales of the Kinosternidae and $740 \quad$ related turtles. Herpetologica, 37, 73-85.

741 Jackson, D. A. (1993). Stopping rules in principal components analysis: a comparison of heuristical and 742 statistical approaches. Ecology, 74, 2204-2214. 
743 Jackson, D. C. (2000). How a turtle's shell helps it survive prolonged anoxic acidosis. Physiology, 15, $744 \quad 181-185$.

745 Jaekel, O. (1914). Über die Wirbeltierfunde in der oberen Trias von Halberstadt. Paläontologische 746 Zeitschrift, 1, 155-215.

747 Gerlach, J. (2004). Effects of diet on the systematic utility of the tortoise carapace. African Journal of $748 \quad$ Herpetology, 53, 77-85.

749 Gunz, P., Mitteroecker, P., \& Bookstein, F. L. (2005). Semilandmarks in three dimensions. In Modern $750 \quad$ morphometrics in physical anthropology (pp. 73-98). Springer, Boston, MA.

751 Gunz, P., \& Mitteroecker, P. (2013). Semilandmarks: a method for quantifying curves and surfaces. 752 Hystrix, 24, 103-109.

753 Joyce, W. G., \& Gauthier, J. A. (2004). Palaeoecology of Triassic stem turtles sheds new light on turtle 754 origins. Proceedings of the Royal Society of London Series B, 271, 1-5.

755 Joyce, W. G., Parham, J. F., \& Gauthier, J. A. (2004). Developing a protocol for the conversion of rank756 based taxon names to phylogenetically defined clade names, as exemplified by turtles. Journal of 757 Paleontology, 78, 989-1013.

758 Joyce, W. G. (2007). Phylogenetic relationships of Mesozoic turtles. Bulletin of the Peabody Museum of 759 Natural History, 48, 3-103.

760 Joyce, W. G. (2015). The origin of turtles: a paleontological perspective. Journal of Experimental 761 Zoology Part B, 324, 181-193.

762 Joyce, W. G. (2017). A review of the fossil record of basal Mesozoic turtles. Bulletin of the Peabody 763 Museum of Natural History, 58, 65-113.

764 Joyce, W. G., \& Mäuser, M. (2020). New material of named fossil turtles from the Late Jurassic (late 765 Kimmeridgian) of Wattendorf, Germany. PLoS ONE, 15, e0233483

766 Joyce, W. G., Rabi, M., Clark, J. M., \& Xu, X. (2016). A toothed turtle from the Late Jurassic of China 767 and the global biogeographic history of turtles. BMC Evolutionary Biology, 16, 236. 
768 Joyce, W. G., Schoch, R. R., \& Lyson, T. R. (2013). The girdles of the oldest fossil turtle, Proterochersis 769 robusta, and the age of the turtle crown. BMC Evolutionary Biology, 13, 266.

770 Klingenberg, C. P. (2016). Size, shape, and form: concepts of allometry in geometric morphometrics.

771 Development Genes and Evolution, 226, 113-137.

772 De Lapparent de Broin, F. (2001). The European turtle fauna from the Triassic to the Present. Dumerilia, $773 \quad 4,155-217$.

774 Lichtig, A. J., \& Lucas, S. G. (2017). A simple method for inferring habitats of extinct turtles.

$775 \quad$ Palaeoworld, 26, 581-588.

776 Lyson, T. R., Bhullar, B. A. S., Bever, G. S., Joyce, W. G., de Queiroz, K., Abzhanov, A., \& Gauthier, J.

777 A. (2013a). Homology of the enigmatic nuchal bone reveals novel reorganization of the shoulder

778 girdle in the evolution of the turtle shell. Evolution \& Development, 15, 317-325.

779 Lyson, T. R., Bever, G. S., Scheyer, T. M., Hsiang, A. Y., \& Gauthier, J. A. (2013b). Evolutionary origin 780 of the turtle shell. Current Biology, 23, 1113-1119.

781 Magwene, P. M., \& Socha, J. J. (2013). Biomechanics of turtle shells: how whole shells fail in compression. Journal of Experimental Zoology Part A, 319, 86-98.

783

784

785

786

787

788

789

McLachlan, G. J. (2004). Discriminant analysis and statistical pattern recognition. Hoboken, NJ: John Wiley \& Sons.

Młynarski M. (1976). Testudines, In Wellnhofer, P. (Ed.), Handbuch der Paläoherpetologie. Stuttgart: Gustav Fischer.

Motani, R., \& Schmitz, L. (2011). Phylogenetic versus functional signals in the evolution of formfunction relationships in terrestrial vision. Evolution, 65, 2245-2257.

Otárola-Castillo, E., Torquato, M. G., Hawkins, H. C., James, E., Harris, J. A., Marean, C. W., McPherron, S. P. \& Thompson, J. C. (2018). Differentiating between cutting actions on bone using 3D geometric morphometrics and Bayesian analyses with implications to human evolution. Journal of Archaeological Science, 89, 56-67.

Pagel, M. (1999). Inferring the historical patterns of biological evolution. Nature, 401, 877 
794 Pereira, A. G., Sterli, J., Moreira, F. R., \& Schrago, C. G. (2017). Multilocus phylogeny and statistical 795 biogeography clarify the evolutionary history of major lineages of turtles. Molecular Phylogenetics 796 and Evolution, 113, 59-66.

797 Polly, P. D., Stayton, C. T., Dumont, E. R., Pierce, S. E., Rayfield, E. J., \& Angielczyk, K. D. (2016).

798 Combining geometric morphometrics and finite element analysis with evolutionary modeling: 799 towards a synthesis. Journal of Vertebrate Paleontology, 36, e1111225.

800 Pritchard, P. (2008). Evolution and structure of the turtle shell. In: Wyneken, J., Godfrey, M., Bels, V. 801 (Eds), Biology of Turtles (pp. 45-83). Boca Raton: CRC press.

802 Püntener, C., Anquetin, J., \& Billon-Bruyat, J. P. (2017). The comparative osteology of Plesiochelys 803 bigleri n. sp., a new coastal marine turtle from the Late Jurassic of Porrentruy (Switzerland). PeerJ, $804 \quad 5$, e 3482.

805 Raselli, I., \& Anquetin, J. (2019). Novel insights into the morphology of Plesiochelys bigleri from the 806 early Kimmeridgian of Northwestern Switzerland. PloS ONE, 14, e0214629.

807 Raselli, I., \& Anquetin, J. (2019). Project: Novel insights into the morphology of Plesiochelys bigleri 808 from the early Kimmeridgian of Northwestern Switzerland. MorphoSource. Available at: http://www.morphosource.org/Detail/MediaDetail/Show/media_id/42034

R Core Team. (2020). R: a language and environment for statistical computing. R Foundation for Statistical Computing, Vienna, Austria. URL https://www.R-project.org/.

812 Ripley, B., Venables, B., Bates, D. M., Hornik, K., Gebhardt, A., Firth, D., \& Ripley, M. B. (2013). Package 'MASS'. Available at: http://cran.r- project.org/web/packages/MASS/MASS.pdf

814 Rivera, G. (2008). Ecomorphological variation in shell shape of the freshwater turtle Pseudemys concinna 815 inhabiting different aquatic flow regimes. Integrative and Comparative Biology, 48, 769-787.

816 Rivera, G., \& Claude, J. (2008). Environmental media and shape asymmetry: a case study on turtle shells.

817 Biological Journal of the Linnean Society, 94, 483-489.

818 Rohlf, F. J., \& Slice, D. (1990). Extensions of the Procrustes method for the optimal superimposition of 819 landmarks. Systematic Biology, 39, 40-59. 
820 Rütimeyer, L. (1873). Die fossilen Schildkröten von Solothurn. Neue Denkschrift der allgemeinen 821 schweizerischen naturforschenden Gesellschaft 25, 1-185.

822 Scheyer, T. M., \& Sander, P. M. (2007). Shell bone histology indicates terrestrial palaeoecology of basal 823 turtles. Proceedings of the Royal Society B, 274, 1885-1893.

824 Stayton, C. T. (2009). Application of thin-plate spline transformations to finite element models, or, how 825 to turn a bog turtle into a spotted turtle to analyze both. Evolution, 63, 1348-1355.

826 Stayton, C. T. (2011). Biomechanics on the half shell: functional performance influences patterns of 827 morphological variation in the emydid turtle carapace. Zoology, 114, 213-223.

828 Szczygielski, T., \& Sulej, T. (2016). Revision of the Triassic European turtles Proterochersis and 829 Murrhardtia (Reptilia, Testudinata, Proterochersidae), with the description of new taxa from $830 \quad$ Poland and Germany. Zoological Journal of the Linnean Society, 177, 395-427.

831 Turtle Taxonomy Working Group [TTWG]. (2017). An annotated list of modern turtle terminal taxa (with 832 comments on areas of instability and recent change). Chelonian Conservation Biology Research

834 Vega, C., \& Stayton, C. T. (2011). Dimorphism in shell shape and strength in two species of emydid 835 turtle. Herpetologica, 67, 397-405.

836 de Vita, J. (1979). Niche separation and the broken-stick model. The American Naturalist, 114, 171-178.

837 Westphal, F. (1976). The dermal armour of some Triassic placodont reptiles. In: Bellairs, A., Cox, C. B. 838 (Eds), Morphology and Biology of Reptiles (pp. 31-41). London: Academic Press.

839 Wieland, G. R. (1903). Notes on the marine turtle Archelon. American Journal of Science, 15, 211-216.

840 Wiesner, C. S., \& Iben, C. (2003). Influence of environmental humidity and dietary protein on pyramidal 841 growth of carapaces in African spurred tortoises (Geochelone sulcata). Journal of Animal $842 \quad$ Physiology and Animal Nutrition, 87, 66-74.

843 Wyneken, J. (1996). Sea turtle locomotion: mechanisms, behavior. In: Lutz, P. L., Musick, J. A. (Eds), 844 The Biology of Sea Turtles (pp. 165-198). Boca Raton, FL: CRC Press. 
845 Zangerl, R. (1969). The turtle shell. In: Gans, C., Bellairs, A. \& Parsons, T. S. (Eds), Biology of the

846 Reptilia (pp. 311-339). London: Academic Press.

847 Zug, G. R. (1971). Buoyancy, locomotion, morphology of the pelvic girdle and hindlimb, and systematics

848 of cryptodiran turtles. Miscellaneous Publications Museum of Zoology, University of Michigan,

$849 \quad 142,1-98$.

850

851

852 Figure captions

853 Figure 1 Landmarks configuration used in the study composed of 10 fixed landmarks and

85412 semilandmark-curves imposed onto a 3D model of the geoemydid Melanochelys trijuga

855 (FMNH 224247). (A) Left lateral view. (B) Anterior view. (C) Posterior view. (D) Dorsal view

856 (grey: epidermal scutes; brown: dermal bones). (E) Ventral view. (grey: epidermal scutes;

857 brown: dermal bones). Abbreviations: ab, abdominal scute; an, anal scute; cv, cervical scute; co,

858 costal; ent, entoplastron; epi, epiplastron; fe, femoral scute; gu, gular scute; hu, humeral scute;

859 hyp, hypoplastron; hyo, hyoplastron; ma, marginal scute; ne, neural; nu, nuchal; pe, pectoral

860 scute; pl, pleural scute; per, peripheral; py, pygal; sp = suprapygal; xi, xiphiplastron.

861

862 Figure 2 Subsamples used in this study. (A) SET1, all landmarks and semilandmarks

863 combined. (B) SET2, outline of the carapace only. (C) SET3, transverse cross-section only. (D)

864 SET4, longitudinal cross-section only. Landmarks are numbered from 1 to 10. Curves composed

865 of semilandmarks are numerated from $\mathrm{C} 1$ to $\mathrm{C} 12$.

866

867 Figure 3 Webbing types of the forehand used for ecological classification. (A) Webbing

868 absent. (B) Poorly webbed, webbing only present at the base of the digits. (C) Fully webbed, 
869 webbing reaches the base of the claws. (D) Webbing extensive, webbing envelopes at least one

870 claw. (E) Manus modified into elongate flipper or paddle. Digits are numbered from 1 to 5 using

871 Roman numerals. Abbreviations: ul, ulna; ra, radius.

872

873 Figure 4 Time-calibrated phylogeny of 72 species used in the study based on Pereira et al.

874 (2017). Abbreviation: Car, Carettochelyidae; Che, Chelydridae; Pel, Pelomedusidae; Pla, 875 Platysternidae; Pod, Podocnemididae.

876

877 Figure 5 Relationship between size and shape. The graph shows regression scores (shape)

878 plotted against $\log (\mathrm{CSize})$ to highlight possible allometric correlations.

879

880

Figure 6 Results of the PCA based on four different dataset configurations. (A) All

881 landmarks and semilandmarks curves, SET1. (B) Outline of the carapace, SET2. (C) Transverse 882 cross-section, SET3. (D) Longitudinal cross-section, SET4. Complete data are available in the 883 Supplementary Files, Table S3.

884

885 Figure 7 Results of the discriminant analysis (LDA) based on four different dataset 886 configurations. (A) All landmarks and curves, SET1. (B) Outline of the carapace, SET2. (C)

887 Transverse cross-section, SET3. (D) Longitudinal cross-section, SET4. All data are available in 888 the Supplementary Files, Table S5.

889

890 Figure 8 Results of the phylogenetic flexible discriminant analysis (pFDA) based on four

891 different dataset configurations. (A) All landmarks and curves, SET1. (B) Outline of the 
892 carapace, SET2. (C) Transverse cross-section, SET3. (D) Longitudinal cross-section, SET4.

893 Complete data are available in the Supplementary Files, Table S6.

894

895 Figure 9 Comparative results of the linear discriminant analysis (LDA) including

896 predictions for fossil species. (A) Analysis using five ecological categories. (B) Analysis using

897 three ecological categories.

898

899 Table legends

900 Table 1 Composition of the extant turtles included in the dataset of this study. Every

901 specimen is associated with a clade, a species name, catalog number, type of preservation (Pres.),

902 ecological category (Cat.) based on webbing ranging ( 0 to 4 ) (see Methods) and acquisition

903 method (Acq.). Abbreviations: DRS, dry skeletal specimen; ETH: complete specimen preserved

904 in ethanol; MUM: complete mummified specimen. SC: 3D Scanner; PH: Photogrammetry

905 reconstruction.

906

907 Table 2 Description of the four different sub-datasets (SET) used in the analyses. The listed

908 landmarks and semilandmarks are shown in Figure 2. Abbreviation: SM, semilandmarks.

909

910 Table 3 Description of ecological categories used in this study based on the webbing of the

911 forelimb as a proxy. Abbreviation: Cat, category.

912

913 Table 4 Confusion matrix showing the recognition of ecological category per SET in the

914 LDA. Each row of the table describes the percentage of correctly identified ecological categories 
915 for each of the four sub-analyses (SET1 to SET4). The last column of the table provides the main

916 error in percent. Complete data are available in the Supplementary Files, Table S4. Abbreviation:

917 Cat, category.

918

919 Table 5 Prediction matrix for the fossils included in the study based on four different

920 dataset configurations based on the linear discriminant analysis (LDA). Complete data are

921 available in the Supplementary Files, Table S7.

922

923 Table 6 Confusion matrix showing the recognition of ecological category per SET in the

924 pFDA. Each row of the table describes the percentage of correctly identified ecological

925 categories for each of the four subsets (SET1 to SET4). The last column of the table provides the

926 main error in percent. Complete data are available in the Supplementary Files, Table S4.

927 Abbreviation: Cat, category.

928

929

Table 7 Prediction matrix for the fossils included in the study based on four different

930

dataset configurations based on the phylogenetic flexible discriminant analysis (pFDA).

931 Complete data are available in the Supplementary Files, Table S7. Abbreviation: NA, not

932 available.

933

934 Table 8 Confusion matrix for the LDA with only three ecological categories applied to

935 SET1 (Misclassification Rate: 18\%). AQ: aquatic (flippers and extensive webbing). SA: semi-

936 aquatic (poorly webbed and fully webbed). TR: terrestrial (not webbed). Rows represent the

937 predictions and columns represent the true ecology. 
938

939 Table 9 Prediction of the ecology fossil turtles based on the LDA for SET1. Results are

940 presented for the analyses using five versus three ecological categories.

941

942 Supplementary Files

943 Figure S1 Histograms summarizing the results for the number of significant PC scores kept

944 for the LDA and the pFDA using the broken-stick model. The y-axis represents the

945 percentage of variation explained by each PC. (A) Model with all collected data, SET1. (B)

946 Outline of the carapace, SET2. (C) Transverse cross section, SET3. (D) Longitudinal cross

947 section, SET4.

948 Figure S2. Mean shapes for each group (category 0 to category 4) of the LDA analysis (SET1 to

949 SET4). (A) "not webbed" (category 0). (B) "poorly webbed" (category 1). (C) "fully webbed"

950 (category 2). (D) "extensive webbing" (category 3). (E) "flippers" (category 4). Mean shapes were

951 computed using the function "mshape" from the $R$ package geomorph.

952

953 Figure S3 Distinctions between ecological categories based on the LD1 values for 5 ecological

954 categories and for 3 ecological categories. (A) The categories not-webbed and flippers are very

955 distinct using 5 categories. The three intermediate categories are overlapping each other. (B) The

956 categories terrestrial and aquatic are very distinct using 3 categories. The intermediate categories are

957 overlapping the terrestrial range.

958

959 Figure S4 Results of the phylogenetic flexible discriminant analysis (pFDA) based on four

960 different dataset configurations using an ultrametric tree. (A) All landmarks and curves,

961 SET1. (B) Outline of the carapace, SET2. (C) Transverse cross-section, SET3. (D) Longitudinal 
962 cross-section, SET4. Phylogenetic tree used in the analysis is available in Supplementary Files,

963 Fig. S5

964

965 Figure S5 Utrametric phylogeny of 72 species used in the study based on Pereira et al.

966 (2017). Abbreviation: Car, Carettochelyidae; Che, Chelydridae; Pel, Pelomedusidae; Pla,

967 Platysternidae; Pod, Podocnemididae.

968

969

Figure S6 Summary of the pDFA analysis using several artificial configurations of outgroup.

970 We tested ways to improve the results on fossil turtles by using an outgroup where all the PC Scores

971 are equal to 0,1 , or randomized scores. The artificial outgroup was tested using two different

972 categorizations, one identified as tnot webbed (category 1), and one as unknown, like the other

973 fossils. Creating this outgroup did not improve the results of the analysis for the fossil turtles.

974 Phylogenetic tree used in the analysis is available in Supplementary Files, Fig. S7.

975

976

977

Figure S7 Time-calibrated phylogeny of 72 species and artificial outgroup used in the study

based on Pereira et al. (2017). Abbreviation: Car, Carettochelyidae; Che, Chelydridae; Pel,

978

Pelomedusidae; Pla, Platysternidae; Pod, Podocnemididae.

979

980

981

Table S1 Proportion of extant turtle genera represented in the dataset as an estimate of

982

sample density. The number of genera for each major clade is based on the TTWG (2007).

983 Abbreviations: Ntotal $=$ number of known genera; Nsample $=$ number of sampled genera.

984 
985 Table S2: Summary table of the 3D models used for this project and their DOI numbers. All

986 specimens reconstructed by us were uploaded on the MorphoSource platform. Available

987

988

Table S3: Principal Component scores (PC Scores) for all configurations (SET1 to SET4).

989

990

Table S4 Detailed table of the confusion table per SET (SET1 to SET4) for the LDA and the

991 pFDA. The cases in green represent the well-recognized turtles. The last line presents the percentage

992 of recognition. 0 : not webbed. 1: poorly webbed. 2 : fully webbed. 3 : extensive webbing. 4 :

993 flippers.

994

995

Table S5 Predictions values and ecological variables resulting from the LDA for each configuration (SET1 -SET4). This table consists of all the extant turtles training dataset.

997

998

999

Table S6 Predictions values and ecological variables resulting from the pFDA for each configuration (SET1 -SET4). This table consists of all the extant turtles training dataset.

1000

Table S7 Results of the linear discriminant analysis (LDA) and the phylogenetical flexible to SET4). The second column represent the predicted class by the model. The five next columns are the prediction values (between 0 and 1) for each ecological category. The four next columns are the results of the discriminant analysis.

1006 


\section{Figure 1}

Landmarks configuration used in the study composed of 10 fixed landmarks and 12 semilandmark-curves imposed onto a 3D model of Melanochelys trijuga (FMNH 224247)
(A) Left lateral view.
(B) Anterior view.
(C) Posterior view.
(D) Dorsal view (grey: epidermal scutes; brown: dermal bones). (E) Ventral view. (grey: epidermal scutes; brown: dermal bones). Abbreviations: ab, abdominal scute; an, anal scute; cv, cervical scute; co, costal; ent, entoplastron; epi, epiplastron; fe, femoral scute; gu, gular scute; hu, humeral scute; hyp, hypoplastron; hyo, hyoplastron; ma, marginal scute; ne, neural; nu, nuchal; pe, pectoral scute; pl, pleural scute; per, peripheral; py, pygal; sp = suprapygal; xi, xiphiplastron.
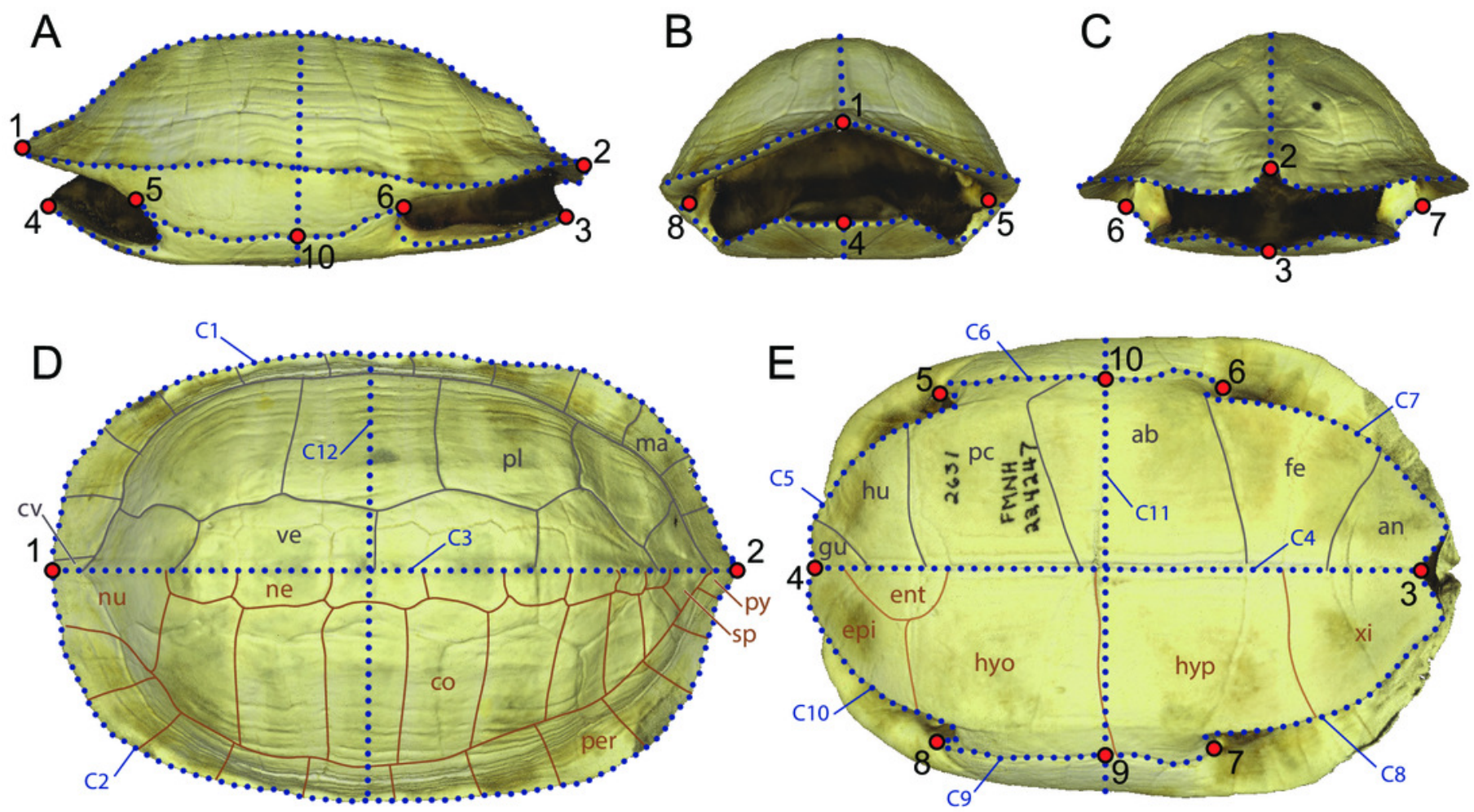
Figure 2

Subsamples used in this study.

(A) SET1, all landmarks and semilandmarks combined. (B) SET2, outline of the carapace only.

(C) SET3, transverse cross-section only. (D) SET4, longitudinal cross-section only. Landmarks are numbered from 1 to 10 . Curves composed of semilandmarks are numerated from $\mathrm{C} 1$ to C12.
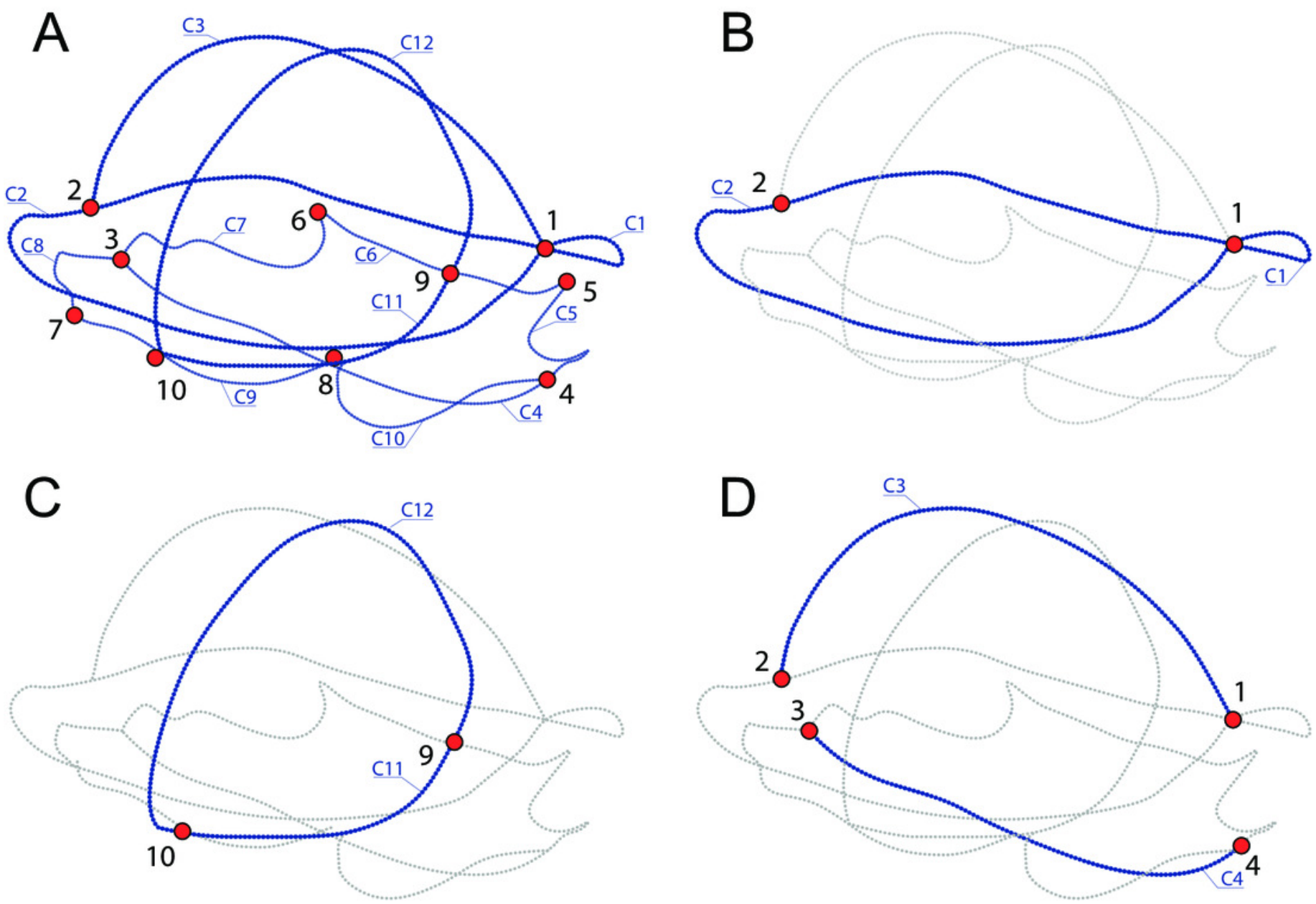
Figure 3

Webbing types of the forehand used for ecological classification.

(A) Webbing absent. (B) Poorly webbed, webbing only present at the base of the digits. (C) Fully webbed, webbing reaches the base of the claws. (D) Webbing extensive, webbing envelopes at least one claw. (E) Manus modified into elongate flipper or paddle. Digits are numbered from 1 to 5 using Roman numerals. Abbreviations: ul, ulna; ra, radius.

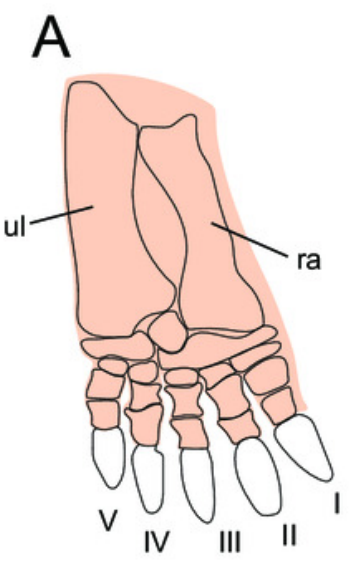

Category 0
B

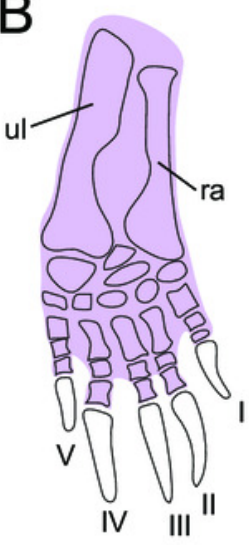

Category 1
C

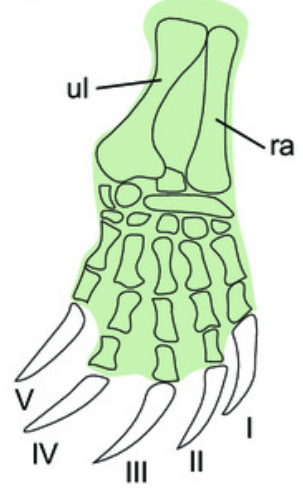

Category 2

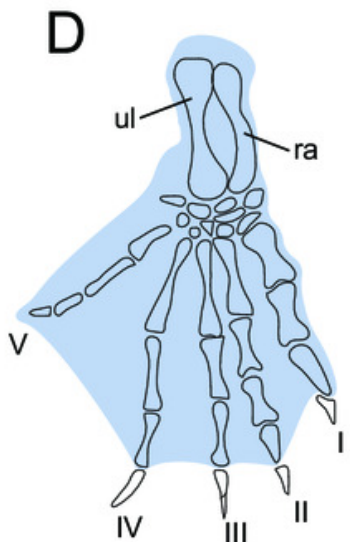

Category 3
E

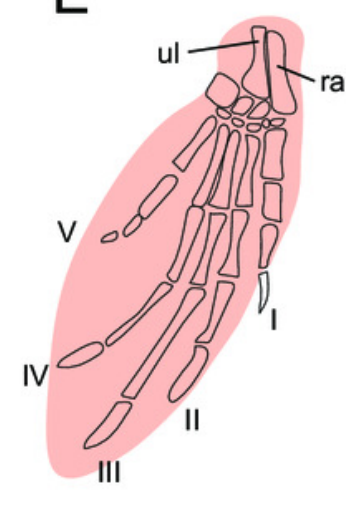

Category 4 
Figure 4

Time-calibrated phylogeny of 72 species used in the study based on Pereira et al. (2017).

Abbreviation: Car, Carettochelyidae; Che, Chelydridae; Pel, Pelomedusidae; Pla, Platysternidae; Pod, Podocnemididae. 


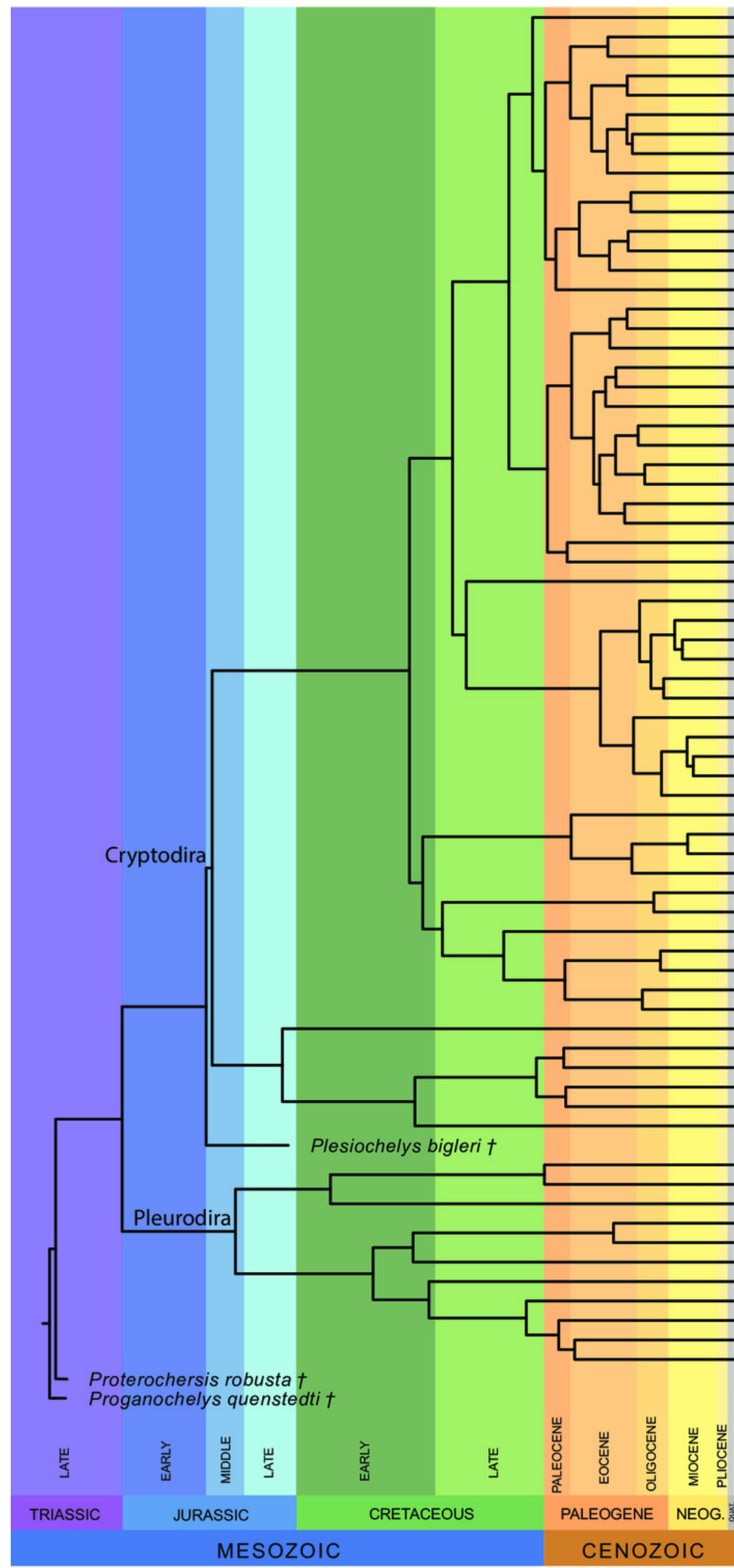

Rhinoclemmys annulata

Melanochelys trijuga

Vijayachelys silvatica

Mauremys reevesii

Cuora amboinensis

Cyclemys dentata

Heosemys spinosa

Notochelys platynota

Sacalia quadriocellata

Malayemys subtrijuga

Orlitia borneensis

Pangshura tentoria

Batagur dhongoka

Morenia petersi

Geoemyda spengleri

Indotestudo elongata

Malacochersus tornieri

Testudo graeca

Kinixys belliana

Geochelone elegans

Chelonoidis carbonaria

Stigmochelys pardalis

Psammobates tentorius

Chersina angulata

Homopus femoralis

Pyxis arachnoides

Astrochelys radiata

Gopherus polyphemus

Manouria impressa

Platysternon megacephalum

Glyptemys insculpta

Actinemys marmorata

Emys orbicularis

Emydoidea blandingii

Terrapene carolina

Clemmys guttata

Deirochelys reticularia

Trachemys scripta

Graptemys geographica

Malaclemys terrapin

Chrysemys picta

Dermochelys coriacea

Caretta caretta

Eretmochelys imbricata

Chelonia mydas

Macrochelys temminckii

Chelydra serpentina

Dermatemys mawii

Staurotypus triporcatus

Claudius angustatus

Sternotherus odoratus

Kinosternon baurii

Carettochelys insculpta

Rafetus euphraticus

Apalone mutica

Dogania subplana

Pelodiscus sinensis

Lissemys punctata

Pelomedusa subrufa

Pelusios sinuatus

Podocnemis vogli

Elseya novaeguineae

Emydura macquarii

Chelodina oblonga

Hydromedusa tectifera

Chelus fimbriata

Mesoclemmys dahli

Phrynops tuberosus

Platemys platycephala
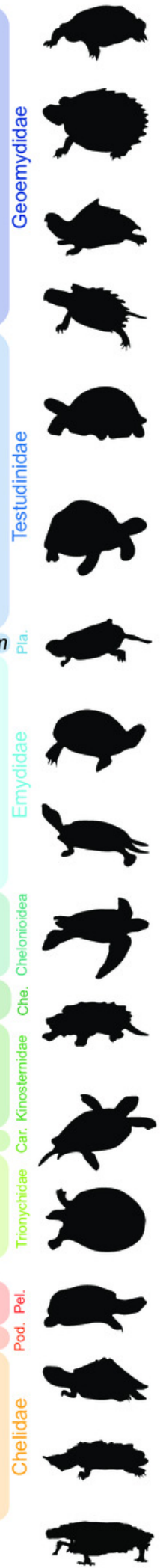

PeerJ reviewing PDF | (2020:04:48096:2:0:NEW 9 Nov 2020) 
Figure 5

Relationship between size and shape.

The graph shows regression scores (shape) plotted against Log(CSize) to highlight possible allometric correlations. 


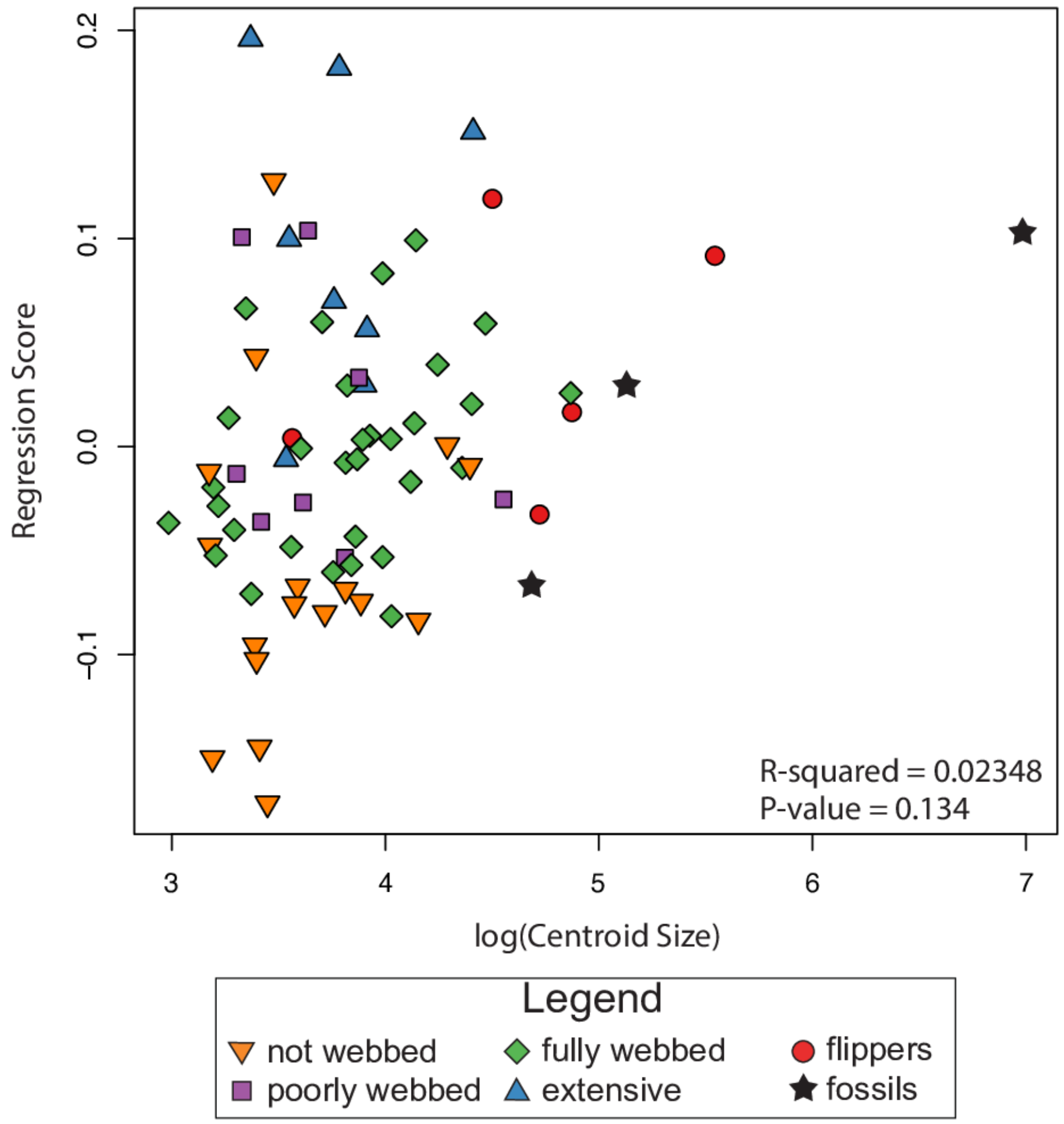


Figure 6

Results of the PCA based on four different dataset configurations.

(A) All landmarks and semilandmarks curves, SET1. (B) Outline of the carapace, SET2. (C) Transverse cross-section, SET3. (D) Longitudinal cross-section, SET4. 


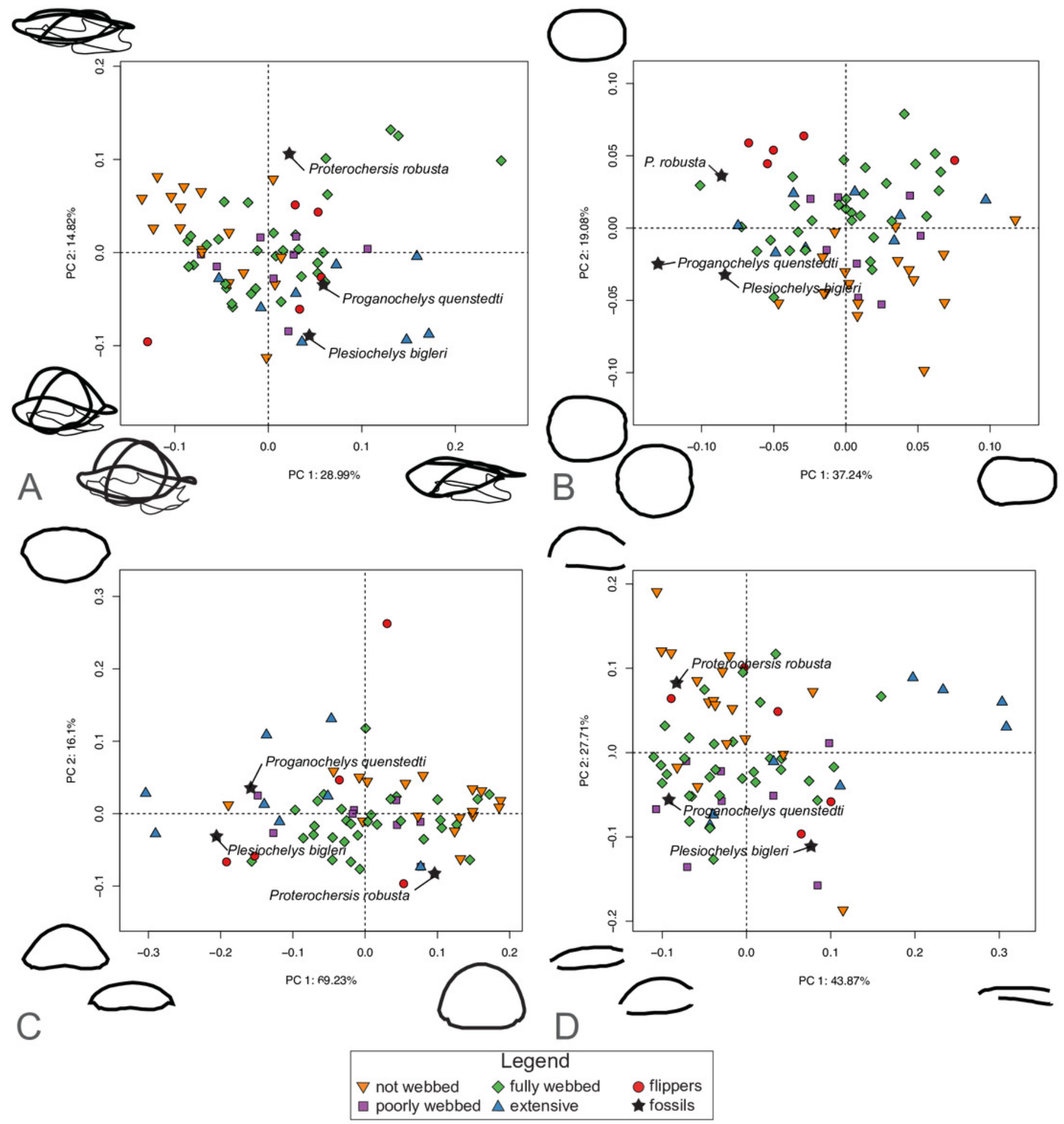




\section{Figure 7}

Results of the discriminant analysis (LDA) based on four different dataset configurations.

(A) All landmarks and curves, SET1. (B) Outline of the carapace, SET2. (C) Transverse crosssection, SET3. (D) Longitudinal cross-section, SET4. All data are available in the Supplementary Files, Table S4. 
A

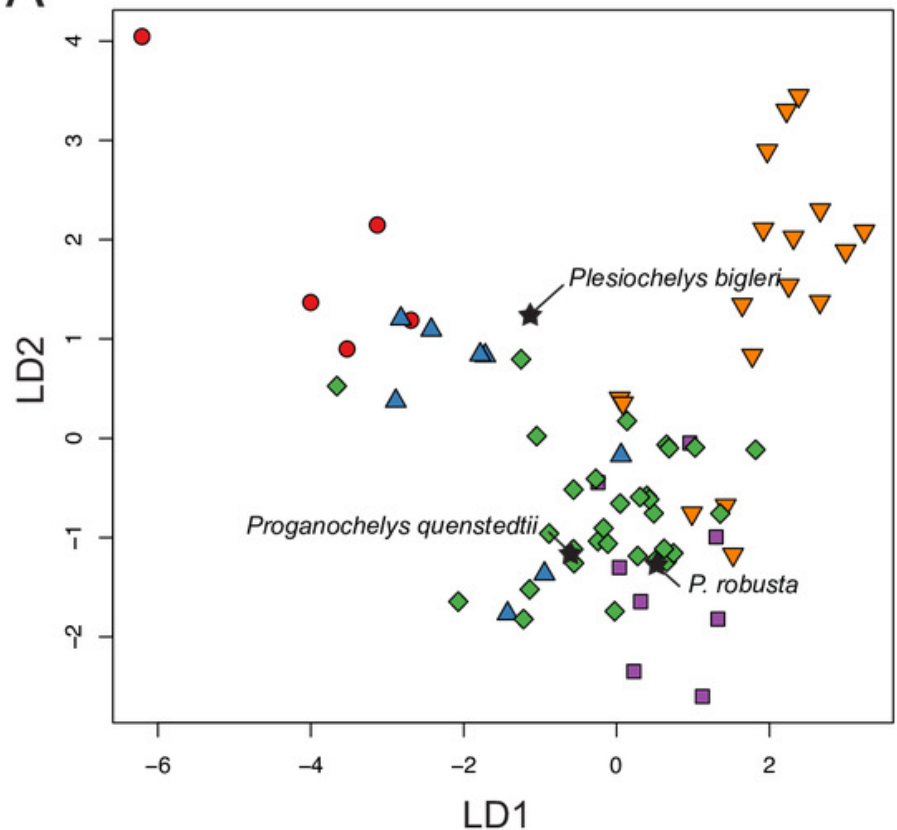

C

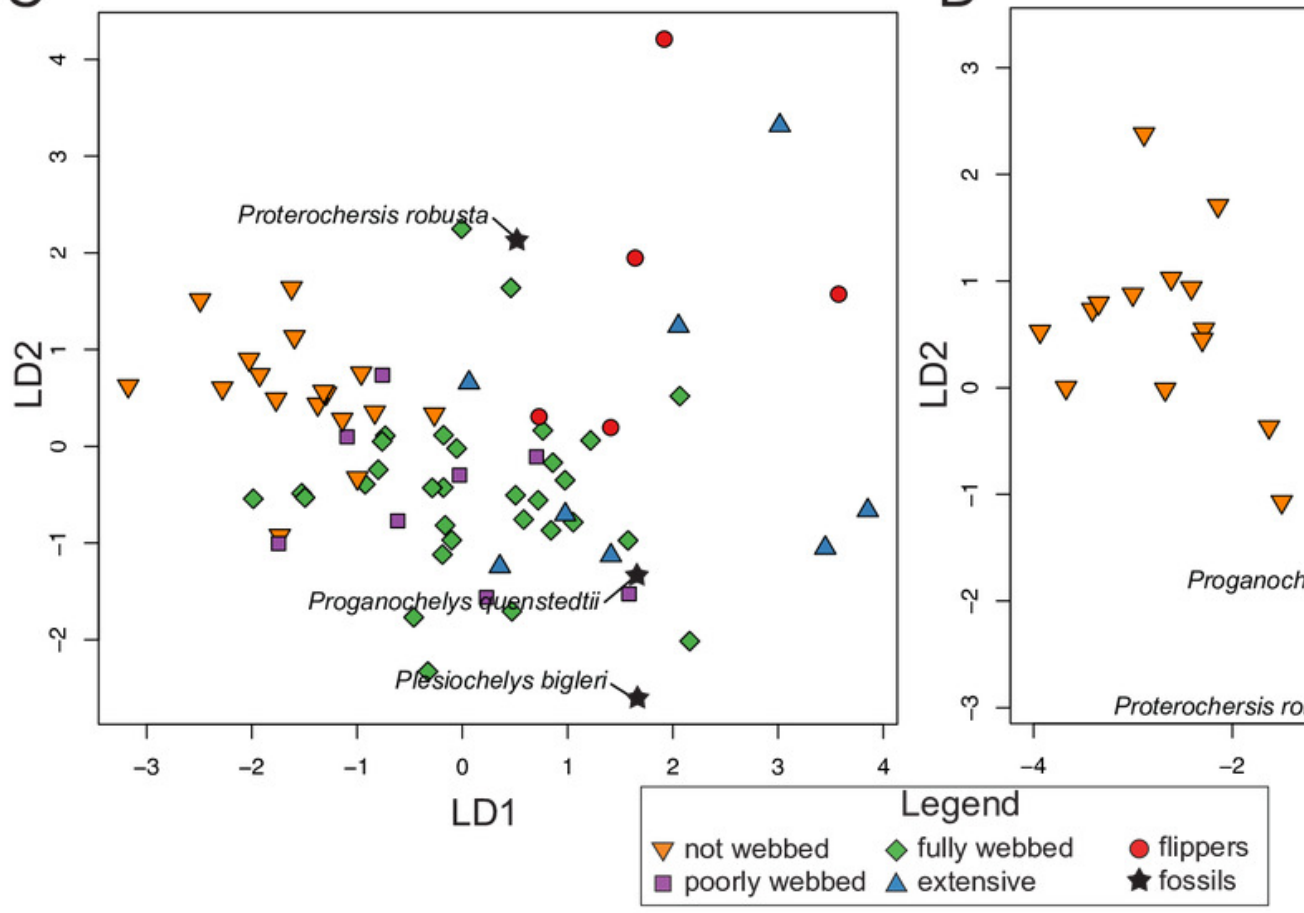

D

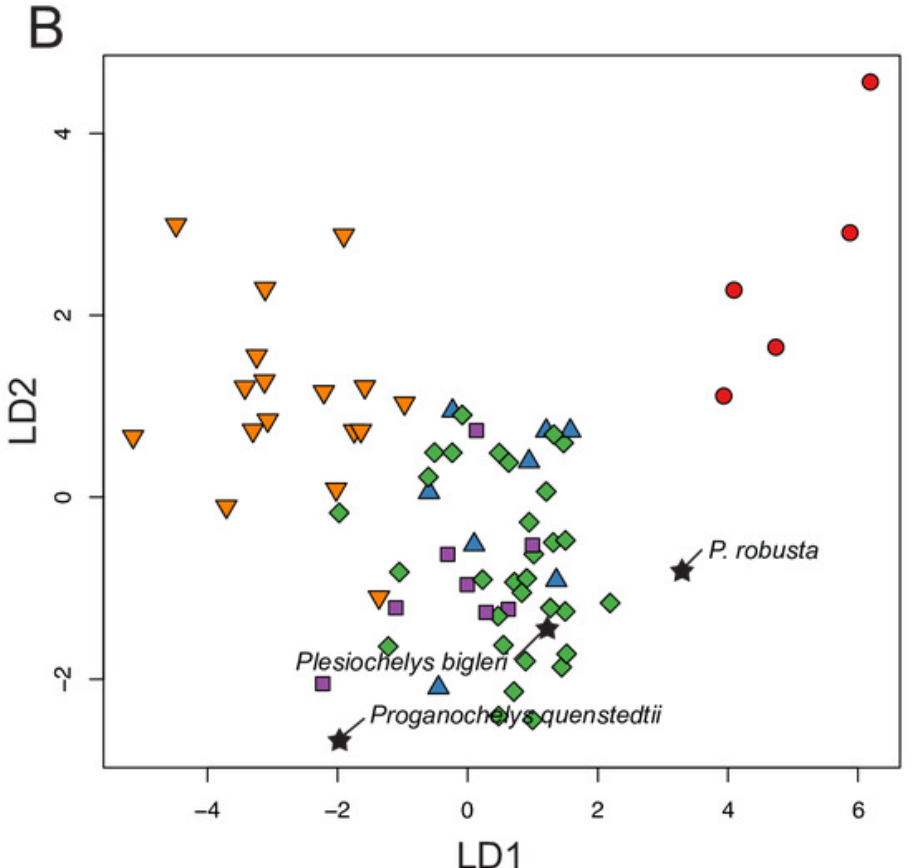


Figure 8

Results of the phylogenetic flexible discriminant analysis (pFDA) based on four different dataset configurations.

(A) All landmarks and curves, SET1. (B) Outline of the carapace, SET2. (C) Transverse cross-

section, SET3. (D) Longitudinal cross-section, SET4. Complete data are available in the Supplementary Files, Table S5. 
A

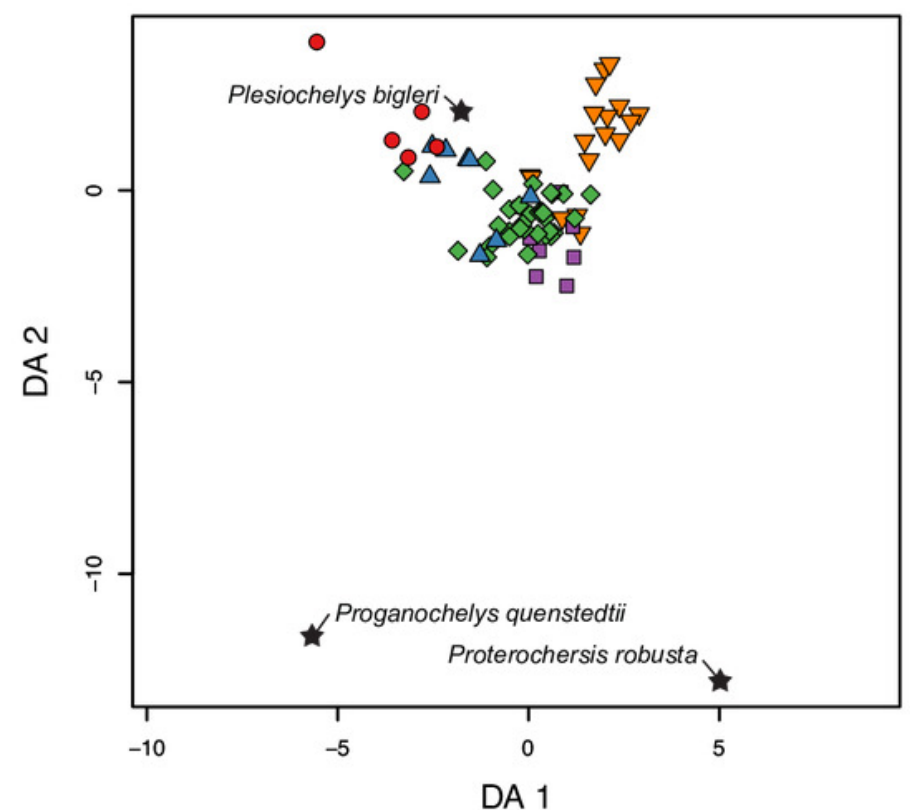

C

$$
\text { ป }
$$

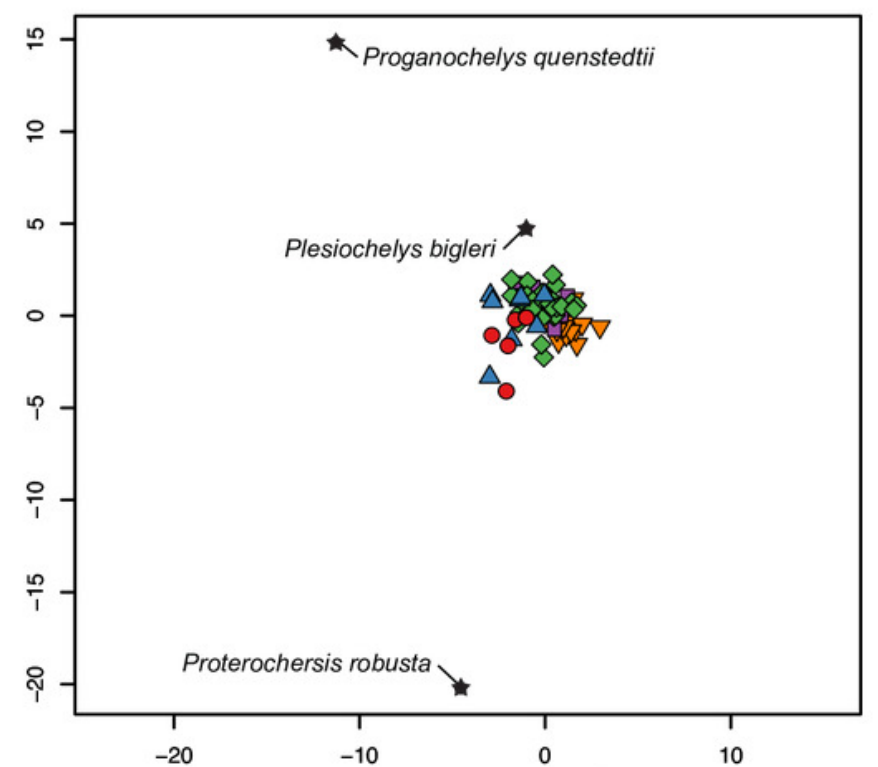

DA 1

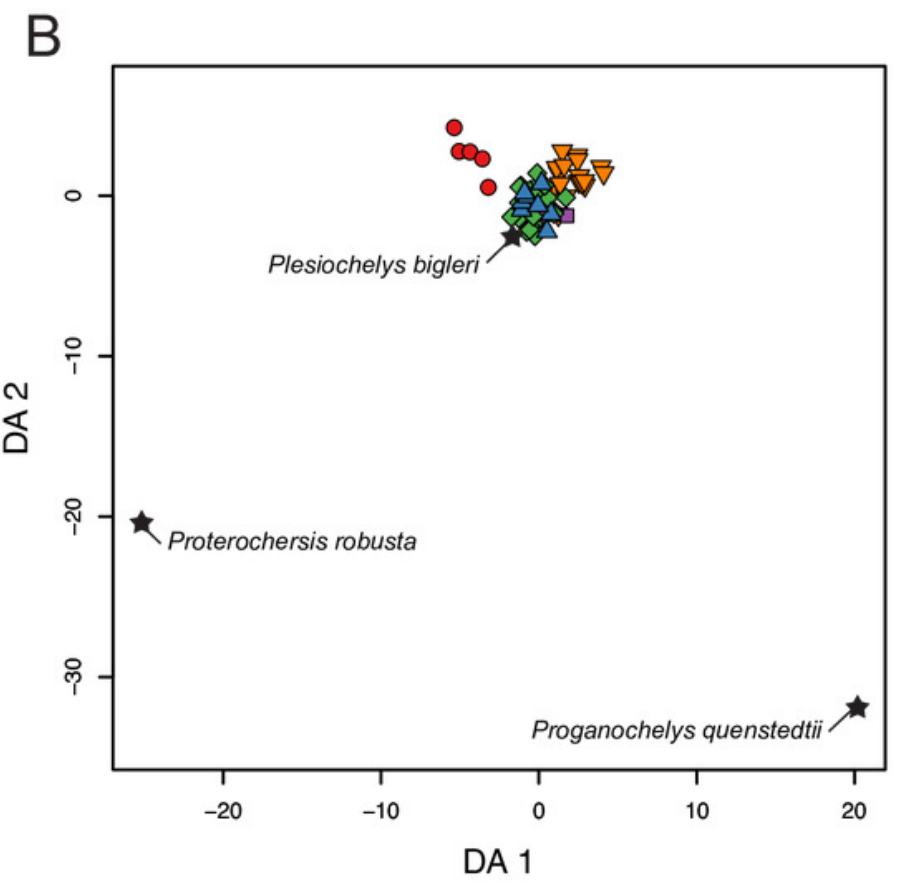

D

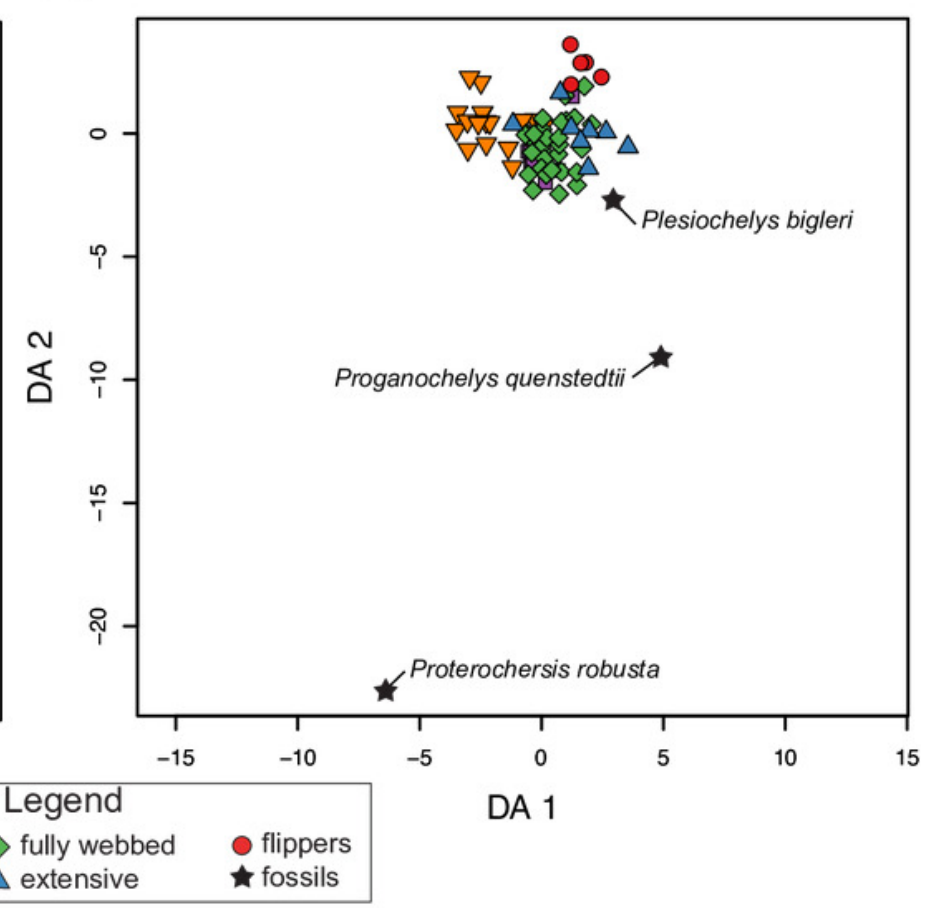


Figure 9

Comparative results of the linear discriminant analysis (LDA) including predictions for fossil species.

(A) Analysis using five ecological categories. (B) Analysis using three ecological categories.

A

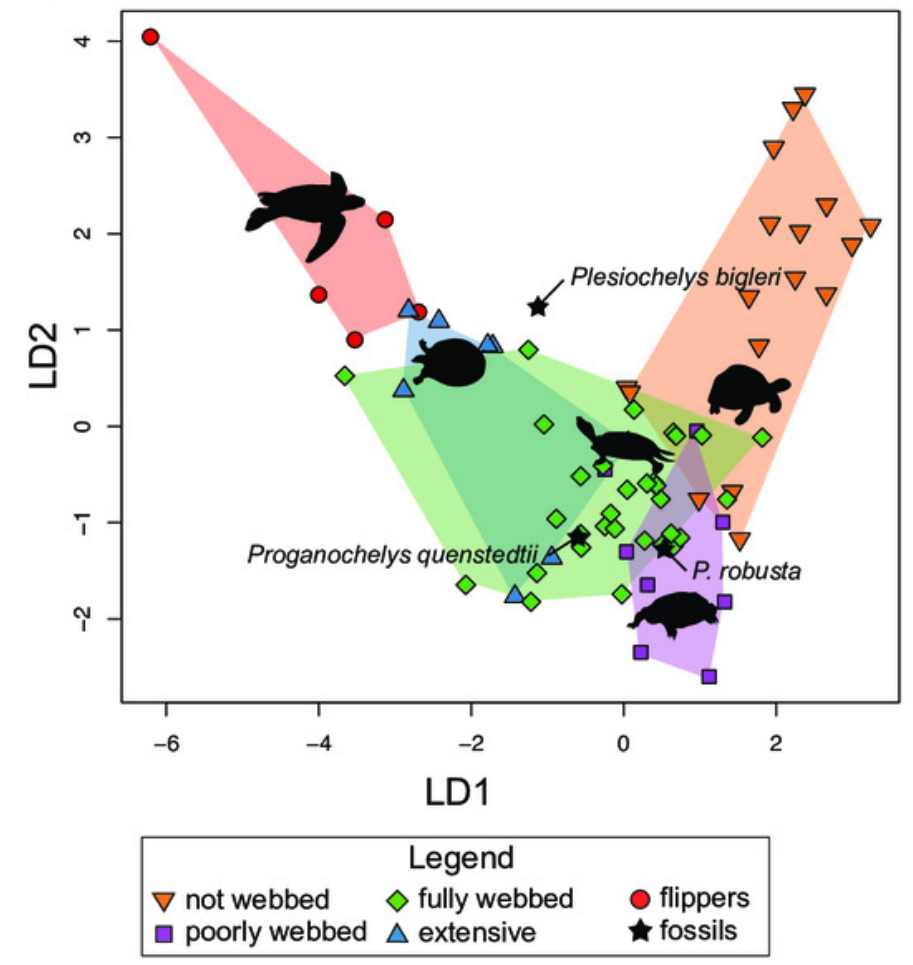

B

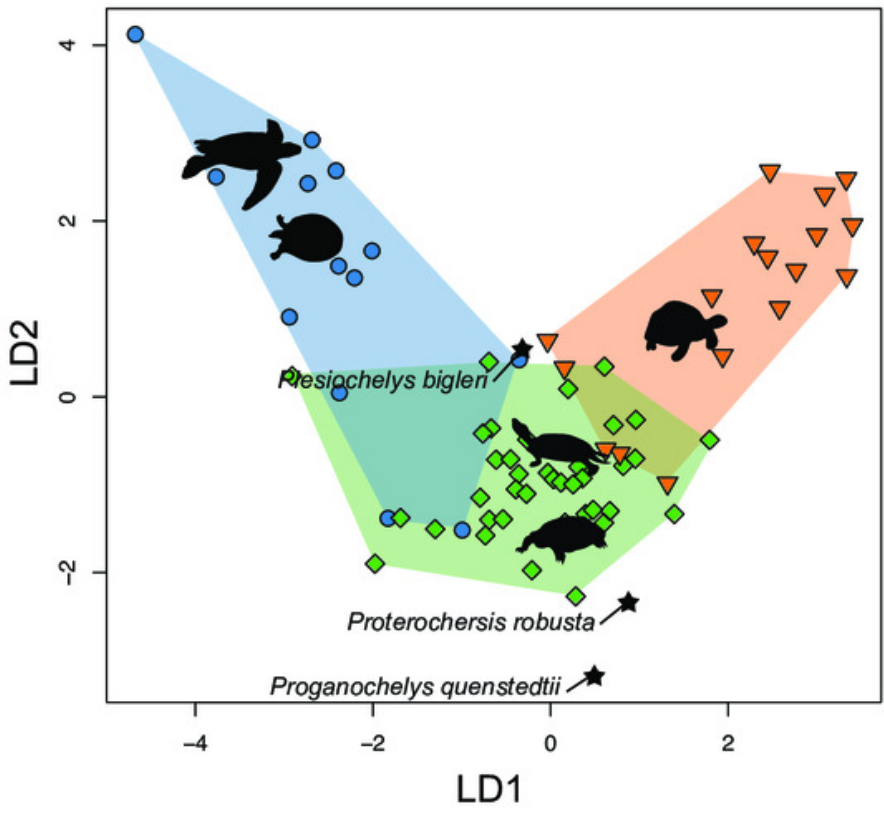

Legend

$\nabla$ specialized terrestrial $\Delta$ specialized aquatic

$\diamond$ intermediate $\star$ fossils 


\section{Table $\mathbf{1}$ (on next page)}

Composition of the extant turtles included in the dataset of this study.

Every specimen is associated with a clade, a species name, catalog number, type of preservation (Pres.), ecological category (Ecol.) based on webbing ranging (0 to 4) (see Methods) and acquisition method (Acq.). Abbreviations: DRS, dry skeletal specimen; ETH: complete specimen preserved in ethanol; MUM: complete mummified specimen. SC: 3D Scanner; PH: Photogrammetry reconstruction. 


\begin{tabular}{|c|c|c|c|c|c|}
\hline Clade & Species & $\begin{array}{l}\text { Catalog } \\
\text { Number }\end{array}$ & Pres & Cat & Acq \\
\hline Carettochelyidae & Carettochelys insculpta & FMNH 15480 & DRS & 4 & SC \\
\hline Chelidae & Platemys platycephala & FMNH 267453 & ETH & 1 & SC \\
\hline Chelidae & Chelus fimbriata & FMNH 250681 & DRS & 2 & SC \\
\hline Chelidae & Mesoclemmys dahli & FMNH 82302 & DRS & 2 & SC \\
\hline Chelidae & Phrynops tuberosus & FMNH 73434 & DRS & 2 & SC \\
\hline Chelidae & Elseya novaeguineae & FMNH 14054 & DRS & 2 & SC \\
\hline Chelidae & Emydura macquarii & FMNH 71793 & ETH & 2 & SC \\
\hline Chelidae & Hydromedusa tectifera & FMNH 217272 & ETH & 3 & SC \\
\hline Chelidae & Chelodina oblonga & FMNH 77997 & ETH & 3 & SC \\
\hline Cheloniidae & Chelonia mydas & NMB 152 & ETH & 4 & $\mathrm{PH}$ \\
\hline Cheloniidae & Caretta caretta & $\begin{array}{l}\text { MHNF } \\
\text { 11858_1993 }\end{array}$ & ETH & 4 & $\mathrm{PH}$ \\
\hline Cheloniidae & Eretmochelys imbricata & NMB 5763 & ETH & 4 & $\mathrm{PH}$ \\
\hline Chelydridae & Macrochelys temminckii & NMB 14 & MUM & 2 & $\mathrm{PH}$ \\
\hline Chelydridae & Chelydra serpentina & FMNH 14710 & DRS & 2 & SC \\
\hline Dermatemydidae & Dermatemys mawii & FMNH 4163 & DRS & 2 & SC \\
\hline Dermochelyidae & Dermochelys coriacea & FMNH 61630 & ETH & 4 & SC \\
\hline Emydidae & Trachemys scripta & FMNH 268818 & DRS & 2 & SC \\
\hline Emydidae & Terrapene carolina & FMNH 211600 & DRS & 0 & SC \\
\hline Emydidae & Clemmys guttata & FMNH 83369 & DRS & 1 & SC \\
\hline Emydidae & Emys orbicularis & FMNH 15654 & MUM & 1 & SC \\
\hline Emydidae & Glyptemys insculpta & FMNH 283801 & DRS & 1 & SC \\
\hline Emydidae & Emys blandingii & FMNH 83439 & DRS & 1 & SC \\
\hline Emydidae & Deirochelys reticularia & FMNH 83401 & DRS & 2 & SC \\
\hline Emydidae & $\begin{array}{l}\text { Graptemys } \\
\text { geographica }\end{array}$ & FMNH 83367 & DRS & 2 & SC \\
\hline Emydidae & Malaclemys terrapin & FMNH 83411 & DRS & 2 & SC \\
\hline Emydidae & Chrysemys picta & FMNH 242270 & DRS & 2 & SC \\
\hline Emydidae & Actinemys marmorata & FMNH 211580 & DRS & 2 & SC \\
\hline Geoemydidae & Geoemyda spengleri & FMNH 260381 & DRS & 0 & SC \\
\hline Geoemydidae & Vijayachelys silvatica & FMNH 224155 & ETH & 0 & SC \\
\hline Geoemydidae & $\begin{array}{l}\text { Rhinoclemmys } \\
\text { annulata }\end{array}$ & FMNH 63923 & DRS & 1 & SC \\
\hline Geoemydidae & Cuora amboinensis & FMNH 224028 & DRS & 2 & SC \\
\hline Geoemydidae & Cyclemys dentata & FMNH 224085 & DRS & 2 & SC \\
\hline Geoemydidae & Heosemys spinosa & FMNH 260383 & DRS & 2 & SC \\
\hline
\end{tabular}




\begin{tabular}{|c|c|c|c|c|c|}
\hline Geoemydidae & Mauremys reevesii & FMNH 6736 & DRS & 2 & SC \\
\hline Geoemydidae & Melanochelys trijuga & FMNH 224247 & DRS & 2 & SC \\
\hline Geoemydidae & Notochelys platynota & FMNH 224050 & DRS & 2 & SC \\
\hline Geoemydidae & Orlitia borneensis & FMNH 224000 & DRS & 2 & SC \\
\hline Geoemydidae & Pangshura tentoria & FMNH 259433 & DRS & 2 & SC \\
\hline Geoemydidae & Sacalia quadriocellata & FMNH 6605 & ETH & 2 & SC \\
\hline Geoemydidae & Malayemys subtrijuga & FMNH 255268 & DRS & 2 & SC \\
\hline Geoemydidae & Morenia petersi & FMNH 260377 & DRS & 2 & SC \\
\hline Geoemydidae & Batagur dhongoka & FMNH 224106 & DRS & 3 & SC \\
\hline Kinosternidae & Claudius angustatus & FMNH 4165 & DRS & 2 & SC \\
\hline Kinosternidae & Staurotypus triporcatus & FMNH 4164 & DRS & 2 & SC \\
\hline Kinosternidae & Sternotherus odoratus & FMNH 83357 & DRS & 2 & SC \\
\hline Kinosternidae & Kinosternon baurii & FMNH 83436 & DRS & 2 & SC \\
\hline Pelomedusidae & Pelusios sinuatus & FMNH 12699 & DRS & 1 & SC \\
\hline Pelomedusidae & Pelomedusa subrufa & FMNH 17173 & DRS & 2 & SC \\
\hline Platysternidae & $\begin{array}{l}\text { Platysternon } \\
\text { megacephalum }\end{array}$ & FMNH 24229 & ETH & 1 & SC \\
\hline Podocnemididae & Podocnemis vogli & FMNH 73419 & MUM & 2 & SC \\
\hline Testudinidae & Astrochelys radiata & FMNH 72598 & ETH & 0 & SC \\
\hline Testudinidae & Chelonoidis carbonaria & FMNH 63916 & DRS & 0 & SC \\
\hline Testudinidae & Chersina angulata & FMNH 83000 & ETH & 0 & SC \\
\hline Testudinidae & Geochelone elegans & FMNH 117829 & MUM & 0 & SC \\
\hline Testudinidae & Gopherus polyphemus & FMNH 83340 & DRS & 0 & SC \\
\hline Testudinidae & Homopus femoralis & FMNH 17178 & MUM & 0 & SC \\
\hline Testudinidae & Indotestudo elongata & FMNH 257382 & DRS & 0 & SC \\
\hline Testudinidae & Kinixys belliana & FMNH 17179 & ETH & 0 & SC \\
\hline Testudinidae & Malacochersus tornieri & FMNH 252435 & DRS & 0 & SC \\
\hline Testudinidae & Manouria impressa & FMNH 263045 & DRS & 0 & SC \\
\hline Testudinidae & Psammobates tentorius & FMNH 17176 & DRS & 0 & SC \\
\hline Testudinidae & Pyxis arachnoides & FMNH 73308 & ETH & 0 & SC \\
\hline Testudinidae & Stigmochelys pardalis & FMNH 29277 & DRS & 0 & SC \\
\hline Testudinidae & Testudo graeca & FMNH 211730 & MUM & 0 & SC \\
\hline Trionychidae & Dogania subplana & FMNH 241342 & ETH & 3 & SC \\
\hline Trionychidae & Pelodiscus sinensis & FMNH 24249 & ETH & 3 & SC \\
\hline Trionychidae & Rafetus euphraticus & FMNH 19492 & ETH & 3 & SC \\
\hline Trionychidae & Apalone mutica & FMNH 7845 & ETH & 3 & SC \\
\hline
\end{tabular}




\begin{tabular}{|l|l|l|l|r|l|} 
Trionychidae & Lissemys punctata & FMNH 73919 & ETH & 3 & SC \\
\hline--- & $\begin{array}{l}\text { Proganochelys } \\
\text { quenstedtii }\end{array}$ & SMNS 16980 & cast & $?$ & PH \\
\hline--- & Proterochersis robusta & SMNS 17561 & fossil & $?$ & PH \\
\hline $\begin{array}{l}\text { Thalassochelydi } \\
\text { a }\end{array}$ & Plesiochelys bigleri & $\begin{array}{l}\text { MJSN CBE- } \\
0002\end{array}$ & fossil & $?$ & SC \\
\hline
\end{tabular}

1 


\section{Table 2 (on next page)}

Description of the four different sub-dataset used in the analyses.

The listed landmarks and semilandmarks are shown in Figure 2. Abbreviation: SM, semilandmarks. 


\begin{tabular}{|l|l|l|l|}
\hline & Description & Landmarks & semiLM \\
\hline SET1 & All landmark data is included. & all & all \\
\hline SET2 & The outline of the of the carapace & 1,2 & C1, C2 \\
\hline SET3 & The transverse cross-section of the shell & 9,10 & C11, C12 \\
\hline SET4 & The longitudinal cross-section of the shell & $1,2,3,4$ & C3, C4 \\
\hline
\end{tabular}

1 


\section{Table 3(on next page)}

Description of ecological categories used in this study based on the webbing of the forelimb as a proxy.

Abbreviation: Cat, category. 


\section{Cat. Webbing type}

Cat.0 Webbing absent. This morphology is associated with an exclusively terrestrial ecology (Fig. 3A).

Cat.1 Minor webbing present between the first phalanges of all fingers (Fig. 3B). This morphology is typical for turtles that spend a moderate amount of time in water.

Cat.2 Extensive webbing present that reaches the ungual phalanx of all digits (Fig. 3C). The associated ecology is semi-aquatic to aquatic in behavior. This is the largest category, including turtles that inhabit lakes, rivers, and ponds and that either swim actively or walk at the bottom.

Cat.3 Extensive webbing present that envelopes at least one digit completely, typically digit $\mathrm{V}$ (Fig. 3D). This category is typical for highly aquatic turtles that rarely leave the water, including several riverine testudinoids and all trionychids.

Cat.4 The forelimb is elongated, the webbing is extensive, and the limb shaped into a soft flipper or hard paddle (Fig. 3E). This category is represented by marine cheloniids and freshwater aquatic carettochelyids. 


\section{Table 4 (on next page)}

Confusion matrix showing the recognition of ecological category per SET in the LDA.

Each line of the table describes the results for each of the four sub-analyses (SET1 to SET4). Each column corresponds to a webbing category. All results are expressed in percent. The last column of the table provides the main error in percent. 


\begin{tabular}{|l|r|r|r|r|r|r|}
\hline & Cat 4 & Cat 3 & Cat 2 & Cat 1 & Cat 0 & Error \\
\hline SET1 & 100 & 50 & 90 & 63 & 70 & 25.31 \\
\hline SET2 & 100 & 50 & 90 & 38 & 94 & 25.61 \\
\hline SET3 & 60 & 50 & 87 & 13 & 88 & 40.43 \\
\hline SET4 & 100 & 63 & 84 & 38 & 76 & 27.93 \\
\hline
\end{tabular}

1

2 


\section{Table 5 (on next page)}

Prediction matrix for the fossils included in the study based on four different dataset configurations based on the linear discriminant analysis (LDA).

Complete data are available in the Supplementary Files, Table S6. 
1

\begin{tabular}{|c|c|c|c|c|}
\hline \multicolumn{2}{|r|}{ SPECIES } & \multirow{2}{*}{$\begin{array}{l}\text { PREDICTION } \\
\text { fully webbed }\end{array}$} & \multirow{2}{*}{$\begin{array}{r}\text { CAT. } \\
2\end{array}$} & \multirow{2}{*}{$\begin{array}{r}\text { PROB. } \\
0.95\end{array}$} \\
\hline SET1 & Plesiochelys bigleri & & & \\
\hline & Proterochersis robusta & fully webbed & 2 & 0.98 \\
\hline & Proganochelys quenstedtii & fully webbed & 2 & 0.99 \\
\hline \multirow[t]{3}{*}{ SET2 } & Plesiochelys bigleri & poorly webbed & 1 & 0.57 \\
\hline & Proterochersis robusta & fully webbed & 2 & 0.98 \\
\hline & Proganochelys quenstedtii & fully webbed & 2 & 0.69 \\
\hline \multirow[t]{3}{*}{ SET3 } & Plesiochelys bigleri & $\begin{array}{l}\text { extensive } \\
\text { webbing }\end{array}$ & 3 & 0.49 \\
\hline & Proterochersis robusta & fully webbed & 2 & 0.38 \\
\hline & Proganochelys quenstedtii & fully webbed & 2 & 0.47 \\
\hline \multirow[t]{3}{*}{ SET4 } & Plesiochelys bigleri & fully webbed & 2 & 0.79 \\
\hline & Proterochersis robusta & fully webbed & 2 & 0.88 \\
\hline & Proganochelys quenstedtii & poorly webbed & 1 & 0.93 \\
\hline
\end{tabular}




\section{Table 6(on next page)}

Confusion matrix showing the recognition of ecological category per SET in the pFDA.

Each line of the table describes the results for each of the four subsets (SET1 to SET4). Each column corresponds to a webbing category. All results are presented in percent. The last column of the table provides the main error in percent. 


\begin{tabular}{|l|r|r|r|r|r|r|}
\hline & Cat 4 & Cat 3 & Cat 2 & Cat 1 & Cat 0 & Error \\
\hline SET1 & 100 & 50 & 94 & 63 & 70 & 24.67 \\
\hline SET2 & 100 & 63 & 94 & 38 & 94 & 22.47 \\
\hline SET3 & 60 & 50 & 87 & 13 & 76 & 42.79 \\
\hline SET4 & 100 & 50 & 83 & 38 & 76 & 30.43 \\
\hline
\end{tabular}

1 


\section{Table 7 (on next page)}

Prediction matrix for the fossils included in the study based on four different dataset configurations based on the phylogenetic flexible discriminant analysis (pFDA).

Complete data are available in the Supplementary Files, Table S7. 
1

\begin{tabular}{l|llrl} 
& SPECIES & PREDICTION & CAT. & PROB. \\
\hline SET1 & Plesiochelys bigleri & flippers & 4 & 0.87 \\
\hline & Proterochersis robusta & fully webbed & 2 & 0.99 \\
\hline \multirow{2}{*}{ SET2 } & Proganochelys quenstedtii & fully webbed & 2 & NaN \\
\hline \multirow{3}{*}{ SET3 } & Plesiochelys bigleri & poorly webbed & 1 & 0.91 \\
\hline & Proterochersis robusta & flippers & 4 & 0.99 \\
\hline & Proganochelys quenstedtii & poorly webbed & 1 & NaN \\
\hline & Proterochersis robusta & flippers & 2 & 0.71 \\
\hline & Proganochelys quenstedtii & extensive & 4 & 0.99 \\
\hline \multirow{2}{*}{ SET4 } & Plesiochelys bigleri & fully webbed & 3 & 0.99 \\
\hline & Proterochersis robusta & fully webbed & 2 & 0.56 \\
\hline & Proganochelys quenstedtii & poorly webbed & 1 & 0.99 \\
\hline
\end{tabular}




\section{Table 8(on next page)}

Confusion matrix for the LDA with only three ecological categories applied to SET1 (Misclassification Rate: 14\%).

AQ: aquatic (flippers and extensive webbing). SA: semi-aquatic (poorly webbed and fully webbed). TR: terrestrial (not webbed). Rows represent the predictions and columns represent the true ecology. 


\begin{tabular}{|l|c|c|c|}
\hline & AQ & SA & TR \\
\hline AQ & 10 & 3 & 0 \\
\hline SA & 1 & 38 & 0 \\
\hline TR & 0 & 5 & 12 \\
\hline
\end{tabular}


Table 9 (on next page)

Prediction of the ecology fossil turtles based on the LDA for SET1.

Results are presented for the analyses using five versus three ecological categories. 
SPECIES

\begin{tabular}{l|l}
\hline CATEGORIES \\
\hline
\end{tabular}

Plesiochelys bigleri

Proterochersis robusta

3 CATEGORIES

Proganochelys quenstedtii

3 CATEGORIES

P

\begin{tabular}{llcl} 
Plesiochelys bigleri & intermediate & $1-2$ & 0.99 \\
\hline Proterochersis robusta & intermediate & $1-2$ & 0.87 \\
\hline Proganochelys quenstedtii & intermediate & $1-2$ & 0.99 \\
\hline
\end{tabular}

